\title{
Thukydides als Therapeut? Berthold Beitz, Golo Mann und Das Geheimnis der Freiheit
}

\author{
Nils Steffensen
}

\section{Zusammenfassung}

Die Studie untersucht die Rezeption des Thukydides und deren geschichtspolitische Funktion in Dror Zahavis Biopic Das Geheimnis der Freiheit (2020), das vom Scheitern der 1974 von Berthold Beitz bei Golo Mann in Auftrag gegebenen Biographie über Alfried Krupp v. Bohlen und Halbach erzählt. In dem Film werden - so die These bundesrepublikanische Kontroversen über Modi des Umgangs mit dem Nationalsozialismus (re-)inszeniert. Dieses Thema besitzt wegen gesellschaftlicher Wandlungsprozesse auch in der Gegenwart, in der sich die Frage nach der Stellung des Nationalsozialismus im Geschichtsbewusstsein neu stellt, eine hohe gesellschaftsdidaktische Relevanz. Als zentrale Argumentationsfigur der Protagonisten im Film dient ein zum Sprichwort mutierter Satz aus dem Epitaphios des Perikles (Thuk. 2,43,4). Die Untersuchung weist nach, wie der Film bei der Nutzung des Zitats in Bezug auf Beitz' Biographie eine Deutungstradition fortschreibt, die Berthold Beitz selbst begründet hat und die von seinem Biographen Joachim Käppner und Bundespräsident Joachim Gauck in das kulturelle Gedächtnis der Bundesrepublik eingeführt worden ist. Es zeigt sich, dass Das Geheimnis der Freiheit seine geschichtspolitischen Ziele nur durch eine fundamentale Manipulation am Wortlaut des Thukydides erreicht, damit jedoch seine erkenntnistheoretischen Prämissen und sein Plädoyer für Professionalität im Umgang mit der Geschichte konterkariert. Der Name des Thukydides, dessen Autorität der Film als historiographische Instanz in Anspruch nimmt, wird so zu einem Etikett ohne Substanz. Durch die unsachgemäße Berufung auf sein Werk werden überdies effektivere, in der deutschen Geschichtskultur angelegte Zugänge zur Debatte über die künftige Bedeutung der nationalsozialistischen Vergangenheit blockiert. Perspektiven für eine konstruktive Rezeption des Thukydides im gesellschaftlichen Diskurs über die Geschichte sieht der Aufsatz im Verzicht auf das Konzept einer historia magistra vitae, das auf der Einebnung von Alteritäten zwischen Vergangenheit und Gegenwart fußt, sowie in der Nutzung des Reflexionspotentials, das Thukydides' Darstellung bietet und das auch in seinem „Methodenkapitel“ (1,20-3) eingefordert wird. Zumindest auf diese Weise besitzt Thukydides eine orientierungsstiftende Aktualität für die Bundesrepublik."

\section{Einleitung}

Träge rollt unter grauem Himmel die Dünung an den Sylter Strand. In der Ferne bemerkt Berthold Beitz die wie aus dem Nichts auftauchende Silhouette einer Frau. Mit zusammengekniffenen Augen fixiert er ahnungsvoll die Erscheinung, verwundert und irritiert zugleich. Vergebens. Die Gestalt gewinnt keine festen Konturen. Bevor er ihr näherkommt, verflüchtigt sie sich so abrupt, wie sie aufgetaucht ist. Immer wieder wird

\footnotetext{
${ }^{*}$ Für instruktive Gespräche bei der Konzeption des Textes möchte ich gerne Silvester Kreisel (Flensburg), für eine sehr hilfreiche Lektüre des Manuskripts den Herausgebern der FeRA, namentlich Professor Krešimir Matijević, meinen herzlichen Dank abstatten.
} 
ihm die Frau in den kommenden Jahren begegnen. Lange bleibt sie unscharf, ist nie fassbar, entzieht sich einer Ansprache. Zermürbt wähnt sich Beitz von einem Geist verfolgt. Erst spät beginnt sich das Rätsel zu lüften.

Die Erscheinung der Frau bildet das allegorische Leitmotiv des erstmals am 15.01.2020 vor einem Publikum von 2,97 Mio. Zuschauern und unter enormer Medienaufmerksamkeit ${ }^{1}$ ausgestrahlten Biopics Das Geheimnis der Freiheit des Regisseurs Dror Zahavi. Mit der Figur rekurriert der Film auf ein autobiographisches Zeugnis des 2013 kurz vor seinem 100. Geburtstag verstorbenen Berthold Beitz, das auf zentrale Geschehniskomplexe seines Lebens und damit zugleich auf den Kern seiner historischen Bedeutung verweist. Nicht nur zählte Beitz als jahrzehntelanger Lenker des Krupp-Konzerns, als Wissenschaftsförderer und als Sportfunktionär über die Unternehmensgeschichte hinaus zu den prägenden Gestalten der Bundesrepublik. Was mehr noch als alle diese Leistungen, so außergewöhnlich sie im Einzelnen wie im Ganzen waren, seinen Namen in das kollektive Gedächtnis einschrieb, waren die Rettungsaktionen, mit denen er zwischen 1941 und 1944 als Generalbevollmächtigter der Karpathen Ö1 AG im ostukrainischen Boryslaw, vorgeblich im Sinne der wirtschaftlichen Interessen des Unternehmens und dabei seine Kontakte zum Besatzungsregime instrumentalisierend, etwa 100 Juden vor der Ermordung durch die nationalsozialistische Vernichtungsmaschinerie bewahrte. ${ }^{2}$ Er selbst sah sich rückblickend zwar nicht als Widerstandskämpfer. ${ }^{3}$ Unbestreitbar ist jedoch, dass er und seine Ehefrau für ihre Hilfsbereitschaft existentielle Risiken eingingen. Mehrfach entkamen sie nur knapp der womöglich tödlichen Enttarnung durch die örtliche SS-Einheit. ${ }^{4}$ Unter Lebensgefahr bewiesen sie „Menschlichkeit als Motiv zur Fürsorge, auch und gerade unter Bedingungen absoluter Inhumanität“" . Für ihre Taten zeichnete die Gedenkstätte Yad Vashem im Jahr 1973 Berthold Beitz und im Jahr 2008 Else Beitz als „Gerechte unter den Völkern“ aus.

Die Erinnerungen an Boryslaw haben Beitz, der bis zu seinem Tod mit Überlebenden in Verbindung stand, zeitlebens nicht losgelassen. „Manchmal“ treibe ihn, so hat er bekannt, die Frage um, ob er mehr hätte tun können. Doch dann stelle er die „Gegenfrage: Wo? Und wann?", die ihn zu der Erkenntnis führe, ,an den Rand des Möglichen gegangen“ zu sein. ${ }^{6}$ Unter Tränen schilderte er in der Rede, die er 1990 in Yad Vashem hielt, wie das Schicksal seiner Sekretärin in ihm hochsteige, die er einst aus einem Deportationszug gerettet hatte, die sich dann aber noch am Bahnsteig entschied - „Ist es erlaubt, Herr Direktor?“ -, in den Zug zurückzukehren und ihre Mutter, deren Freilassung ein SS-Offizier verweigert hatte, in den Tod zu begleiten. ${ }^{7}$

In Das Geheimnis der Freiheit verkörpert die Sekretärin, die sich hinter der immer wiederkehrenden Erscheinung verbirgt, die blass gewordene, jedoch immer noch präsente Erinnerung an das Grauen von Boryslaw. Anhand einer semifiktionalen, aber

\footnotetext{
${ }^{1}$ S. hierzu Anm. 15.

2 Die umfassendste wissenschaftliche Darstellung zu dieser Phase in Beitz' Biographie bietet SANDKÜHLER 1996, 290-424. Für eine prägnante Zusammenfassung der Rettungsaktionen s. SANDKÜHLER 2004, 110-3; 118, wobei die Zahl der zwischenzeitlich geretteten, später aber doch noch ermordeten Juden um ein Vierfaches höher gewesen sein dürfte. Zu Beitz' Tätigkeit in Boryslaw s. ferner KÄPPNER 2010 und PÖTZL 2011, 64-95 sowie auch SCHMALHAUSEN 1991. Zur Frage der wirtschaftlichen Interessen s. SANDKÜHLER 2004, 103; 109. Für die Ausnutzung der Beziehungen zur Besatzungsmacht vgl. den besonders prominenten Fall Hildebrand; hierzu KÄPPNER 2010, 92-6; 355-74.

${ }^{3}$ BEITZ 2008A sowie KÄPPNER 2010, $100 \mathrm{f}$.

${ }^{4}$ Für eine Bilanz s. SANDKÜHLER 2004, 117 mit 107 sowie PÖTZL 2011, 48 f. für die Widerlegung der später gegen Beitz vorgebrachten Kritik, ihn habe in Wirklichkeit ein wirtschaftliches Kalkül geleitet.

${ }^{5}$ SANDKÜHLER 2014, 117.

${ }^{6}$ BEITZ 2008A.

${ }^{7}$ S. hierzu KÄPPNER 2010, 16-8 (Zitat 17).
} 
historisch informierten Erzählung der Entstehung der letztlich gescheiterten Biographie über Alfried Krupp v. Bohlen und Halbach (1907-1967), den Reorganisator des KruppKonzerns, mit der Beitz 1976 den Historiker Golo Mann beauftragte, eröffnet der Film einen Einblick in die Erinnerungskultur der Bundesrepublik der 1970er und 1980er Jahre, indem er zwei gegensätzliche, in Gesellschaft und Politik dominierende Strategien im Umgang mit der nationalsozialistischen Vergangenheit einander gegenüberstellt: die Forderung nach Verschweigen und Vergessen sowie den Appell zur aktiven Auseinandersetzung mit dem „Dritten Reich“.

Längst ist es zwar gesellschaftlicher Konsens, dass die Erinnerung an die Verbrechen des Nationalsozialismus zum Selbstverständnis der Bundesrepublik gehört. Die Inszenierung dieser Kontroverse, deren Positionen im Film von den beiden Protagonisten Beitz und Mann (gespielt von Sven-Eric Bechtolf und Edgar Selge) personifiziert werden, besitzt jedoch auch im Rahmen aktueller Diskurse ein Potential für Sinnstiftung. Mit der zunehmenden chronologischen Distanz zum Nationalsozialismus, dem generationellen Wandel und der durch Heterogenisierung der Gesellschaft hervorgerufenen Pluralisierung des Geschichtsbewusstseins stellt sich eindringlich die Frage, welche Zukunft die Auseinandersetzung mit der nationalsozialistischen Vergangenheit im Zeichen neuartiger politischer, gesellschaftlicher und ökonomischer Herausforderungen noch besitzt, denen sich die vermeintlich gefestigte, historisch endgültig belehrte, international als Vorbild für Erinnerungspolitik geltende Demokratie gegenüber sieht und sehen wird. Als Hindernis könnte sich künftig nicht, wie früher, die Abwehr von Schuld oder Verstrickung erweisen, sondern die Gleichgültigkeit, die aus einer vermeintlichen Irrelevanz der Geschichte resultiert. Beide Formen einer verweigerten Auseinandersetzung mit der Vergangenheit haben ungeachtet aller Verschiedenheiten in ihren Zielen und Begründungen gemeinsam, dass ihnen eine radikale, von der Vergangenheit ganz und gar losgelöste Zukunftsorientierung zugrunde liegt. Wenn aber jede Konstruktion von Geschichte eine „Sinnbildung über Zeiterfahrung “8 darstellt, die durch eine „Verschmelzung der Zeithorizonte ${ }^{\text {"9 }}$ Vergangenheit, Gegenwart und Zukunft entsteht, lässt sich der Film vor dem Hintergrund dieses Wandels als ein gesellschaftsdidaktisches Plädoyer begreifen, die Geschichte des Nationalsozialismus auch im 21. Jahrhundert im Zentrum des bundesrepublikanischen Geschichtsbewusstseins zu verankern. Zahavi selbst sieht in Beitz' Streben nach Einfluss, das vom unbedingten Willen zur Gestaltung der Zukunft geleitet wurde, und der Notwendigkeit zu Kompromissen die Ursache für die nicht opportune Auseinandersetzung mit der Geschichte ${ }^{10}$ eine Situation, wie sie unter anderen Vorzeichen prinzipiell wieder eintreten könnte.

Das argumentative Instrument, mit dem beide Protagonisten operieren, bildet ein prominentes, im Filmtitel aufgegriffenes Zitat aus Thukydides' Peloponnesischem Krieg. Es entstammt dem Epitaphios, der Rede des Perikles auf die Gefallenen des ersten Kriegsjahres. In dieser Ansprache lässt Thukydides den führenden Athener Politiker jener Zeit bei dem Versuch, die Kriegsbereitschaft der Bürger zu mobilisieren, einen funktionalen Zusammenhang zwischen Glück, Freiheit und Mut herstellen. ${ }^{11} \mathrm{Im}$ Film verstehen Beitz und Mann dieses Dictum als eine Art lebensphilosophische Einsicht und adaptieren sie für ihre persönliche Situation.

\footnotetext{
${ }^{8}$ RÜSEN 1983, 51.

${ }^{9}$ GADAMER 1975, 281-90.

10 ZAHAVI 2020. Seiner Auffassung nach war für Beitz die Sorge vor dem Widerstand ehemaliger Nationalsozialisten entscheidend: ,Und er hat das in seiner Position und auch für die Kontakte, die er für seine Arbeit und die Entwicklung von Krupp brauchte, nicht als großen Vorteil gesehen, ein - in Anführungszeichen - ,Judenfreund“ zu sein. Deshalb hat er das klein gehalten und ein bisschen versteckt.“

11 Thuk. 2,43,4; für den Wortlaut und eine Übersetzung s. u. S. 69.
} 
Abwegig ist dieser Kunstgriff Zahavis nicht. Einerseits ist das Zitat in der Öffentlichkeit schon länger eng mit Berthold Beitz verbunden. Er selbst hat den Satz des Perikles im Jahr 2008 in einem Zeitungsinterview zur Erklärung seiner Rettungsaktionen bemüht. Diese auf die Geschehnisse von Boryslaw bezogene Selbstdeutung hat Joachim Käppner dann 2010 in seiner Beitz-Biographie auf das ganze Leben von Beitz ausgedehnt. Mit eigener Akzentsetzung hat schließlich Bundespräsident Gauck bei der Trauerfeier für den Manager gewissermaßen von Staats wegen den Zusammenhang zwischen Beitz' Biographie und dem Thukydides-Zitat bestätigt. Andererseits erhebt Thukydides selbst den Anspruch auf eine überzeitliche, niemals erlöschende Aktualität seiner historischen Forschungen. ${ }^{12}$ Die Lektüre seines Werks soll, wie er betont, ausdrücklich keinen ästhetischen Genuss vermitteln. Vielmehr will die Darstellung durch ihre inhaltliche Substanz ein $\kappa \tau \tilde{\eta} \mu \alpha \underline{\varepsilon} \varsigma$ $\alpha$ i̇ì („Besitz für immer“) bereitstellen, ${ }^{13}$ dessen Dauerhaftigkeit auf einer präzisen Analyse der menschlichen Natur beruht. Diesem Verständnis zufolge ist die Geschichte die sich zu jedem beliebigen Zeitpunkt konkretisierende Ausprägung anthropologischer Bedingtheiten. Gelinge es, aus historischen Phänomenen die ihnen zugrundeliegende unveränderliche Substanz zu extrahieren, dann würden - seinem Ansatz zufolge - Strukturen und Muster sichtbar werden, deren Kenntnis das Verständnis für jeweils vergleichbare Konstellationen ermögliche und dadurch geradezu wissenschaftlich fundierte Handlungsspielräume und -optionen eröffne. Die Geschichte bietet nach Thukydides somit keine enzyklopädischen Lektionen, die aus verbindlichen Beispielen und Lehrsätzen für alle erdenklichen Einzelfälle bestehen, sondern ist ein hermeneutisches Instrument zur Analyse der in ihrer Funktionsweise stets gleichbleibenden Mechanik des menschlichen Handelns und der Politik.

Die seit 2400 Jahren andauernde, zur Popularisierung einladende Attraktivität der szientistisch imprägnierten Ausrichtung des Peloponnesischen Kriegs, deretwegen Thukydides im 19. Jahrhundert zu einem Archetypen der Politikwissenschaft stilisiert wurde, ${ }^{14}$ spiegelt sich noch in der sprichwortmäßigen Verdichtung wider, in der Berthold Beitz das Werk bekannt ist. So bietet Das Geheimnis der Freiheit einen zeitgeschichtlichen Testfall für die Aktualität des Thukydides. Nicht nur besaß Perikles' Definition von Glück und deren Voraussetzungen tatsächlich einen Erkenntniswert für die historische Person Berthold Beitz und ebenso, wenngleich mit teilweise anderen Absichten, für seinen Biographen und den Bundespräsidenten. An Beitz' Selbstzeugnis anknüpfend, diente Zahavi die Inszenierung einer mit existentieller Ernsthaftigkeit und philologischen Mitteln sowie unter Berufung auf geschichtswissenschaftliche Standards geführten Debatte über die adäquate Auslegung des Zitats als Vehikel für einen Beitrag zum Diskurs über Gegenwart und Zukunft des Geschichtsbewusstseins der Deutschen.

Seine Rezeption des Thukydides wirft allerdings das Problem auf, ob Thukydides wirklich die Lösung für ein gegenwärtiges erinnerungspolitisches Problem anbietet. Zwar erlaubt gerade die Zeitlosigkeit, die Thukydides für seine Erkenntnisse postuliert, deren Übertragung auf andere Kontexte. Doch gemäß den erkenntnistheoretischen Prä-

\footnotetext{
${ }^{12}$ Die komplexen Probleme zu erörtern, die sich mit den geschichtstheoretischen Grundlagen von Thukydides' Geschichtswerk, namentlich dem Methodenkapitel, verbinden, ist an dieser Stelle aus pragmatischen Gründen ausgeschlossen. Der hier gebotene, notgedrungen extrem summarische Überblick orientiert sich an den maßstabsetzenden Studien, die Kurt A. Raaflaub vorgelegt hat und die auf breite Anerkennung gestoßen sind (RAAFLAUB 2006, 2013, 2016). Für einen allerersten Zugang zu Detailfragen der thukydideischen Historik sowie weiterer Literatur s. jetzt FORSDYKE 2017.

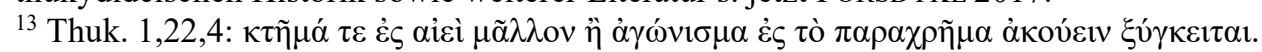

${ }^{14}$ S. hierzu MUHLACK 2011.
} 
missen des Werkes bedürfen die vorgeblich mit naturwissenschaftlicher Präzision gewonnenen Einsichten, die Thukydides nur selten explizit formuliert, einer exakten und adäquaten Interpretation, die durch jede Änderung des Textes und des Sinnzusammenhangs verfälscht werden würde. Es stellt sich daher die Frage, inwieweit die in dem Epitaphios angelegte Lehre mit der Verwendung des Zitats im Film in Deckung gebracht werden kann. Sie ist eng mit dem Modus der Aneignung von Antike verbunden, die Zahavi in seinem Film praktiziert. Von der Antwort hängt ab, ob die Berufung auf Thukydides einen inhaltlichen Mehrwert besitzt und ob der Weisheits- und Legitimationsanspruch, der offenbar Thukydides angeheftet wird, tatsächlich gerechtfertigt ist. Ins Allgemeine gewendet, ergeben sich daraus Erkenntnisse über die Chancen der Berufung auf die Antike, aber auch über damit verbundene Grenzen und Probleme.

Diesen Komplexen möchte die Studie unter der Fragestellung „Thukydides als Therapeut?" nachgehen. Angestrebt ist dabei keine Gesamtinterpretation von Das Geheimnis der Freiheit, so sehr sie der gedankenreiche und tiefgründige Film verdient. ${ }^{15}$ Auch soll das Biopic weder einer systematischen Überprüfung auf Historizität unterzogen noch in den Kontext von Thematisierungen des Nationalsozialismus im Spielfilm eingeordnet werden. Ebensowenig wird beabsichtigt, einen Beitrag zu Problemen der Thukydides-Forschung wie der Auslegung des Epitaphios, der Konstruktion der Person des Perikles oder den politischen Intentionen des Historikers zu leisten. Die hier angestellte Untersuchung fokussiert sich stattdessen im konzeptionellen Rahmen der Thukydides-Rezeption auf die geschichtspolitische Instrumentalisierung des Perikles-Satzes durch eine dreifach kontextualisierte Konfrontation der von den Filmfiguren Berthold Beitz und Golo Mann verfochtenen Interpretationen der Stelle. Als Erstes präsentieren eine Vorstellung des Biographie-Projekts und der wahrscheinlichen Ursachen seines Scheiterns sowie eine Einordnung des Epitaphios in die Geschichte Athens und in Thukydides' Peloponnesischen Krieg das historische Ausgangsmaterial des Films (II). Die Übersetzungen und Auslegungen des Zitats im Rahmen der Handlung werden

${ }^{15}$ Das Geheimnis der Freiheit hat ein größtenteils kritisches, allerdings inhaltlich wenig aussagekräftiges Medienecho ausgelöst, das alle vom Film aufgeworfenen Probleme offenlässt. Überraschenderweise haben sich auch Leitmedien wenig oder gar nicht mit dem intellektuellen Gehalt des Films auseinandergesetzt, sondern sind zumeist in einer ästhetisierenden Kritik der Inszenierung steckengeblieben (so z. B. A. Cammann, URL: www.zeit.de/2020/03/das-geheimnis-der-freiheit-ard-film-berthold-beitz-golomann; J. Freitag, URL: https://www.rnd.de/medien/biopic-das-geheimnis-der-freiheit-beitz-als-schuldbeladener-wohltater-4VCLNZCUC5C27J3HGN4WMB5FRA.html; W. Höbel, URL: https://www.spiegel.de/kultur/tv/das-geheimnis-der-freiheit-in-der-ard-die-geisterjaeger-a-60cd9f3e-1e 06-4bd7-aab21b58086299fc; Th. Gehringer, URL: http://www.tittelbach.tv/programm/fernsehfilm/artikel-5448.html; W. Winkler, URL: https://www.sueddeutsche.de/medien/ard-fernsehen-krupp-das-geheimnis-der-freiheit-1.4753516.

Das vom Film verhandelte Problem des Umgangs mit der Vergangenheit und ihrem Fortwirken greifen dagegen explizit auf: T. P. Gangloff, https://www.evangelisch.de/inhalte/164751/15-01-2020/tv-tippdas-geheimnis-der-freiheit-151-ard-2015-uhr; N. v. Festenberg, URL: https://www.tagesspiegel.de/gesellschaft/medien/berthold-beitz-und-golo-mann-schuld-aus-stahl/25432798.html; K. Knitterscheidt, URL: $\quad$ https://www.handelsblatt.com/unternehmen/industrie/fernsehkritik-krupp-manager-bertholdbeitz-der-letzte-ruhrbaron/25430534.html?ticket=ST-245644-Dh9YvMydRIOTRmqFqqa6-ap5 und O. Jungen, URL: https://www.faz.net/aktuell/feuilleton/medien/historisches-dialog-drama-im-erstendas-geheimnis-der-freiheit-16581124.html?printPagedArticle=true\#pageIndex 2. (Alle Rezensionen wurden am 01.02.2020 abgerufen).

Auch an diesen Besprechungen ist jedoch zu beobachten, dass die Kritiker keine Fragen an die Bedeutung und Sinnhaftigkeit des Films stellen. Die Einordnung des Films in aktuelle gesellschaftliche Diskurse über die Geschichte und seine Relevanz als geschichtskulturelles Produkt im Hinblick auf die orientierungsstiftende Funktion von Geschichte (Gegenwarts- und Zukunftsorientierung) bleiben unerörtert. Forschungen zu dem anregenden Film, die in diese Richtung zielen, sollten aus kulturgeschichtlicher und geschichtsdidaktischer Sicht sowie aus der Perspektive der Public History als ein Desiderat zu betrachten sein. 
danach, jeweils ausgehend von einer philologischen Bestimmung ihres Bezugs zum griechischen Wortlaut, einer inhaltlichen Analyse unterzogen und als exemplarische Positionen zum Umgang mit dem Nationalsozialismus in den erinnerungskulturellen Diskurs der 1970er und 1980er Jahre verortet (III, IV). Ein Vergleich arbeitet daraufhin das Verhältnis zwischen den beiden Aneignungen des Zitats und dem Original heraus und bietet eine Erklärung für die narratologische Notwendigkeit von Modifikationen des Textes an (V). Im Anschluss wird gezeigt, wie Zahavi bei der Verwendung des Zitats als tragendes Element des Plots auf die mehrschichtige Tradition der Selbst- und Fremddeutung der Person Berthold Beitz zurückgreift und ihr im Interesse eigener geschichtspolitischer Ziele eine neue Facette hinzufügt (VI). Die Analyse dreht sich also um unterschiedliche historische Ebenen sowie Fiktionalisierungen und Deutungen von Vergangenheit. Vor dem Hintergrund all dieser Zusammenhänge stellt sich die Frage, ob der Perikles-Satz als ein „Besitztum“ zumindest für die Gestaltung der bundesrepublikanischen Erinnerungskultur geeignet ist und Thukydides jedenfalls hinsichtlich dieses Problems über Aktualität verfügt (VII). Am Schluss stehen knappe Überlegungen zur erinnerungspolitischen Privilegierung der Antike gegenüber dem Potential gegenwärtiger Deutungs- und Lösungsstrategien (VIII).

\section{Das historische Material des Films}

Die Geschichte des Projekts der Biographie von Alfried Krupp, die Berthold Beitz bei Golo Mann bestellte, erstreckte sich von 1974 bis $1981 .{ }^{16}$ Nach der Veröffentlichung der monumentalen Wallenstein-Biographie 1973 war Mann in eine Schaffenskrise geraten, in der er eine Vielzahl unterschiedlicher Sujets als Gegenstand einer neuen Monographie sondierte, ohne dass diese Vorhaben je über das Anfangsstadium hinaus gelangten. ${ }^{17}$ In dieser Zeit erreichte ihn die Anfrage von Berthold Beitz, der ihn als Nachlassverwalter Krupps und Vorsitzender der Krupp-Stiftung einlud, eine biographische Darstellung Krupps zu dessen 70. Geburtstag zu verfassen. Die Firma Fried. Krupp war nach dem Krieg zum Symbol für den Erfolg der Bundesrepublik geworden, stand aber auch für die Verwicklungen der deutschen Industrie im Nationalsozialismus. Obwohl das Unternehmen von der Rüstungswirtschaft profitiert hatte, war es keine „treibende Kraft hinter den entscheidenden Weichenstellungen der NS-Politik“ gewesen. ${ }^{18}$ Alfried Krupp war dennoch als Kriegsverbrecher verurteilt worden. Nach seiner Entlassung aus der Haft 1951 stellte sich das Unternehmen unter seiner Leitung und dem von ihm berufenen Generalbevollmächtigten Berthold Beitz neu auf und bemühte sich, auch durch die Gründung der Krupp-Stiftung, um eine nachhaltige Imageverbesserung. ${ }^{19}$

Was Mann aus Beitz' Sicht für den Auftrag qualifiziert haben dürfte, waren sowohl seine Popularität, die sich damals auf ihrem Höhepunkt befand, als auch seine Erfahrung mit dem Genre der Biographie, in dem er durch den Wallenstein sowie durch

\footnotetext{
${ }^{16}$ Für die Einzelheiten s. BITTERLI 2005, 647-59 und LAHME 2009, 287-91 aus der Perspektive Manns sowie KÄPPNER 2010, 406-13 und PÖTZL 2011, 16-23 aus dem Blickwinkel von Beitz.

${ }^{17}$ BITTERLI 2005, 647-9; LAHME 2009, 287 f.

18 S. hierzu JAMES 2011, 7 f.; 231 (Zitat).

19 JAMES 2011, 248 f.; 251; 253-5; 268-70. Warum Krupp Beitz verpflichtete, der keinen Bezug zur Stahlindustrie hatte, lässt sich nicht aufklären. Zu möglichen Gründen, die auch in Beitz' Aktivitäten in Boryslaw wurzeln können, s. die Überlegungen von PÖTZL 2011, 128 f.; 139 f.; 205. Die nicht völlig komplikationslos verlaufenden Bemühungen des Konzerns um Wiedergutmachung in der Nachkriegszeit, die sich letztlich als bemerkenswerter Erfolg von Krupp und Beitz erwiesen, stellt GaLL 2002C, 550-7 dar.
} 
kleinere Portraitskizzen ausgewiesen war. Obwohl Mann vergleichbare Angebote aus der Industrie abgelehnt hatte, ${ }^{20}$ ließ er sich nach längeren Verhandlungen auf das Vorhaben ein, für das er keine inhaltliche Anteilnahme verspürte, das jedoch die Phase seiner literarischen und wissenschaftlichen Orientierungslosigkeit $\mathrm{zu}$ beenden versprach. Für die Publikation wurde das Jahr 1978 anvisiert. In seinem Tagebuch notierte er: „Das sollte ich wohl nicht tuen. Sollte.“21

Nur zögerlich nahm Mann die Arbeit an dem Buch auf. Erst Monate vor dem vereinbarten Erscheinungstermin begann er mit Archivrecherchen und der Befragung von Zeitzeugen. Wegen seiner Phobie vor dem Thema zog sich das Projekt quälend hin. Immer wieder wurde die Veröffentlichung hinausgeschoben. Als Mann 1981 schließlich ein Typoskript ${ }^{22}$ einreichte, das etwa zwei Drittel des fertigzustellenden Buches umfasste, zog der offenbar hochgradig unzufriedene Beitz die Reißleine. Nach einer Konsultation von Krupps Bruder und des Kuratoriums der Stiftung teilte er dem überraschten Historiker bei einem Arbeitsessen den Abbruch des Vorhabens mit. Trotz einer großzügigen Abfindung und trotz seines inneren Widerstands gegen das Thema reagierte Mann mit Empörung. ${ }^{23}$ Beitz stellte ihm daraufhin frei, das ursprünglich geplante Buch in Form eines längeren biographischen Essays zu publizieren, unternahm also keine Anstalten, ein Erscheinen der Arbeit mit juristischen Mitteln ${ }^{24} \mathrm{zu}$ unterbinden.

Die Gründe für die Beendigung der Zusammenarbeit erläuterte Beitz Mann nicht. ${ }^{25}$ Dass das ursprüngliche Ziel der Auftragsarbeit, eine Geburtstagswürdigung von Alfried Krupp, schon längst obsolet geworden sei, hatte der skeptisch gewordene Beitz bereits 1980 festgestellt, sich aber ausdrücklich von einer Fortsetzung der Arbeit überzeugen lassen. Die Annahme, dass er ein Jahr später den Glauben an die Fertigstellung des Buches verloren haben soll, ${ }^{26}$ ist nicht unvorstellbar, aber angesichts des inzwischen weitgediehenen Texts eher unwahrscheinlich. Da Beitz den Abbruch des Projekts offenbar unmittelbar und in großer Eile ${ }^{27}$ nach dem Eingang des Typoskripts initiierte, liegt es nahe, die Ursache für sein resolutes Vorgehen weniger im komplizierten Entstehungsprozess und in einer mangelnden Perspektive für die Veröffentlichung als im Text selbst und in Beitz' Lektüreeindruck zu suchen. Einwände gegen die Darstellung, die aus Krupps, des verurteilten Kriegsverbrechers, Verhalten im Nationalsozialismus

\footnotetext{
${ }^{20}$ BitTERLI 2005, 649.

${ }^{21}$ Zit. n. LAHME 2009, 389, der in diesem Zusammenhang auch einen Tagebucheintrag Manns aus dem Jahr 1977 anführt: „Vor Krupp fürchte ich mich. Was soll er mir?“ S. ferner PöTZL 2011, 23.

${ }^{22}$ Vgl. Krupp. 2. Fassung (s. Quellenverzeichnis).

${ }^{23}$ BITTERLi 2005, $653 \mathrm{f}$.

${ }^{24}$ Gegen Käppner, der auf diesen Aspekt besonderen Wert legt, könnte allerdings eingewandt werden, dass der versierte Menschenkenner, der Beitz war, nach dem von ihm forcierten Ende des Projekts davon ausgehen konnte, dass Mann aufgrund seiner fehlenden intrinsischen Motivation auch die Essayfassung nicht abschließen würde. Insofern müssen Vermutungen darüber, was Beitz unternommen hätte, wäre das Buch auf Manns private Initiative tatsächlich fertiggestellt worden, Spekulation bleiben.

${ }^{25}$ LAHME 2009, 391.

${ }^{26}$ KÄPPNER 2010, 410.

${ }^{27}$ Nach dem Bericht der Nichte Alfried Krupps, Diana Maria Friz, soll Beitz Krupps Bruder, Berthold v. Bohlen und Halbach, genötigt haben, über Nacht ein negatives Urteil über den Text abzugeben, um mit diesem Votum Druck auf das Stiftungskuratorium auszuüben. Nicht nur habe Berthold v. Bohlen und Halbach später bedauert, dieser Aufforderung nachgekommen zu sein. Auch habe die Familie nach eingehender Lektüre des Buchfragments eine positive Einschätzung der Darstellung gewonnen und sich auch später für eine Publikation ausgesprochen. Näheres zu diesen privaten Vorgängen bei FRIZ 1988, 35 f.; 235. Friz' polemische Monographie über Berthold Beitz und Alfried Krupp ist zwar in den Kontext der langjährigen, auch vor Gericht ausgetragenen Konflikte einzuordnen, die Teile der Familie v. Bohlen und Halbach mit Beitz um die Auslegung von Krupps Testament austrugen, doch spricht für ihre Erläuterung der Hintergründe, dass sie sich mehrfach auf ein gutes Verhältnis zu Mann berufen kann und auch ein Fragment aus dem Typoskript in ihrem Buch abdruckt (30-3).
} 
hätten herrühren können, hielt selbst der düpierte Autor für ausgeschlossen. ${ }^{28}$ Wahrscheinlich liegt, wie auch er vermutete, der Grund für Beitz' brüske Reaktion in der historischen Einordnung von Krupps Wirken als Direktor der Krupp-Konzerns. Krupp war Mann nicht nur von der Persönlichkeit her fremd und bar jeder Faszination - „viel Feuer gibt er keinesfalls her" ${ }^{\text {29. }}$. Insofern war Beitz möglicherweise über die Schilderung von Krupps komplexem Privatleben und Manns eigentümlichem Fokus auf dem von ihm als wesentlich interessanter empfundenen Gustav Krupp, einer übermächtigen Vaterfigur, irritiert. Ausschlaggebend könnte aber gewesen sein, dass Mann Krupp auch als unternehmerische Gestalt und Wirtschaftslenker für eine ,ziemliche Null“ hielt, zu der Beitz jedoch, wie dem Historiker selbst bewusst war, eine „eigentlich rührende Vasallentreue ${ }^{\text {“30 }}$ gehalten habe.

Es dürften daher weder die NS-Verwicklungen der Firma oder Alfried Krupps noch die Unzufriedenheit mit einzelnen Elementen des Narrativs, die im Überarbeitungsprozess hätten korrigiert werden können, ${ }^{31}$ für Beitz' Ablehnung der Biographie maßgeblich gewesen sein, sondern die blasse, unscheinbare Rolle, die Mann dem Helden zugeschrieben hatte, jener Person, dem Beitz als Generalbevollmächtigter und Testamentsvollstrecker sechs Dezennien seines fast einhundert Jahre währenden Lebens gewidmet hat. Eine „Kaiser-Geburtstagsrede“, die Beitz vielleicht erwartet haben könnte, hatte Mann von vornherein verweigert. ${ }^{32}$ Womöglich war er aus Beitz' Perspektive schlicht an der biographischen Sinnstiftung gescheitert. Die psychologisch grundierte These Käppners, dass Beitz' das Gefühl eines drohenden Kontrollverlusts leitete, das er seit dem Nationalsozialismus zutiefst hasste, ${ }^{33}$ ist mit geschichtswissenschaftlicher Methodik nicht beweisbar, könnte allerdings - wie noch deutlich werden wird - einen kaum zu überschätzenden Einfluss auf den Film ausgeübt haben.

Just aber die hypothetische, von der Forschung einhellig zurückgewiesene Möglichkeit, dass Manns Darstellung der Verwicklung Alfried Krupps in den Nationalsozialismus das Biographie-Projekt zum Scheitern brachte, liegt dem Plot und der Botschaft von Das Geheimnis der Freiheit zugrunde. Den Arbeitsprozess an der Biographie erzählt der Film als ein Ringen zwischen Golo Mann und Berthold Beitz um den Umgang

\footnotetext{
${ }^{28}$ Mann nannte die Biographie wegen Krupps Loyalität zum nationalsozialistischen Regime zu Beginn der Arbeit zwar ein „,heikles Unterfangen“ (BITTERLI 2005, 651), fällte jedoch ein ebenso abgewogenes wie nachvollziehbares Urteil über die Verstrickung der Firma Fried. Krupp und ihres Direktors in das „Dritte Reich“ (Originalmanuskript, „Krupp im Dritten Reich“), dessen Tendenz den modernen Forschungsstand zur Unternehmensgeschichtsschreibung vorwegnimmt (s. hierzu JAMES 2011, 231, dessen Einschätzung sich mit der umfassenden Darstellung von ABELSHAUSER 2002 zur Geschichte von Fried. Krupp im „Dritten Reich“ deckt). Alfried Krupp persönlich erscheint als apolitischer (Originalmanuskript, „Krupp im Dritten Reich“, 12) und moralisch eher indifferenter (13 f.) Technokrat, der mit Blick für die Chancen des Unternehmens „,einstweilen“ die „Vorzüge [des „Dritten Reichs“, N.St.] so viel bedeutender als die Schattenseiten“ empfand, „,dass man diese ebenso gut ignorieren konnte“ (12 f.; Zitat 12). Den Opportunismus Krupps ordnet Mann unaufgeregt, wenn nicht gar abgeklärt ein und lässt ihn dabei als Typus des unspektakulären Mitläufers erscheinen (13 f.).

${ }^{29}$ Tagebucheintragung vom 08.07.1975, zit. n. LAHME 2009, 389.

${ }^{30}$ BITTERLI 2005, $655 \mathrm{f}$.

${ }^{31}$ So ließe sich die These von KÄPPNER 2010, 410 relativieren, wonach die Rolle Gustav Krupps sowie die privaten Enttäuschungen Alfried Krupps wichtige Gründe für die Zurückweisung des Texts abgegeben haben könnten.

${ }^{32}$ Dies ist auch die Vermutung von Krupps Schwägerin, Edith v. Bohlen und Halbach (vgl. hierzu LAHME 2009, 391). Möglicherweise war aber auch die weitgespannte Einleitung dazu angetan, Beitz’ Missvergnügen auszudrücken, da Mann hier den Mythos der Firma Fried. Krupp als „Waffenschmiede“ aufruft und Alfred Krupp mit dem zweiten „Mythos“ des 19. Jahrhunderts, Richard Wagner, parallelisiert (Originalmanuskript, ,„Vorgeschichte“, 1-11, bes. 1 f.).

${ }^{33}$ KÄPPNER 2010, 413.
} 
mit der Vergangenheit und deren Relevanz für die Gestaltung von Gegenwart und Zukunft. Alfried Krupps Haltung zum Nationalsozialismus bietet dabei für die Handlung nur den Anlass. Was der Historiker und der Manager tatsächlich verhandeln, sind existentielle Fragen, die ihren jeweiligen Lebensläufen eingeschrieben sind. Im Mittelpunkt stehen dabei die Traumata, die Beitz während seiner Tätigkeit für die Karpathen Öl AG in Boryslaw bei seinen Rettungsaktionen und bei Konfrontationen mit dem nationalsozialistischen Regime erlitten hat. ${ }^{34}$ Der Streit zwischen Beitz und Mann über die Frage, ob die Vergangenheit im Interesse der Gegenwart durch Verschweigen ausgeblendet oder durch Erinnern neutralisiert werden müsse, kulminiert in einer Auseinandersetzung über die zutreffende Deutung des berühmten Zitats aus dem Epitaphios des Perikles, das Beitz' Lebensmotto bildet und auf das auch der Filmtitel anspielt.

Epitaphioi waren seit den Perserkriegen eine Institution der politischen Kultur Athens. ${ }^{35}$ Sie bildeten den alljährlichen Höhepunkt der Bestattungsfeierlichkeiten für die Gefallenen, die nicht individuell, sondern als Gruppe geehrt wurden. Als „Diskurse

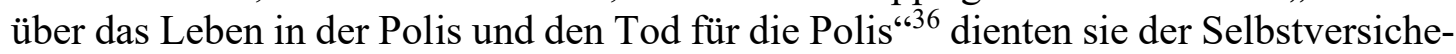
rung Athens, indem sie im Angesicht der versammelten Bürgerschaft wie auch der anwesenden Fremden durch die Formulierung grundlegender politischer Werte, Tugenden und Ziele zur Entwicklung und Konsolidierung des Bürgerbewusstseins beitrugen.

Den Anlass des Epitaphios im Geschichtswerk des Thukydides bildet die Würdigung der Gefallenen aus dem ersten Jahr des Peloponnesischen Krieges. Bei dem durch sein besonderes Ansehen ausgezeichneten Bürger, der traditionell als Redner ausgewählt wurde,${ }^{37}$ handelt es sich um Perikles, die entscheidende Gestalt der athenischen Politik der Zeit. Seine Figur im Peloponnesischen Krieg ist ein Konstrukt des Thukydides, deren authentische Züge sich kaum identifizieren lassen. Fest steht allerdings, dass der Historiker ihn zum Muster des vollkommenen Staatsmanns stilisiert. ${ }^{38}$ So ist zumindest im Wortlaut auch der Epitaphios ein Produkt des Thukydides. ${ }^{39}$ Der Satz, um dessen Auslegung der Film kreist, steht am Schluss der Parainese (2,41,5-43,6), die an die Bereitschaft der Athener zum Kriegsdienst appelliert $(43,4)$ :

\footnotetext{
${ }^{34}$ Der Vollständigkeit halber sei ergänzt, dass der Film, wenngleich eher nebenbei, auch das Ringen von Golo Mann und Else Beitz um Freiheit thematisiert. Bei Mann handelt es sich um die Befreiung von der Familie, namentlich dem Übervater Thomas Mann, aber auch, in späten Jahren, von der Mutter Katia, wobei der Film auch auf die Diskriminierung der Homosexualität anspielt, bei Beitz um das Nachholen von in ihrer Jugend unzugänglichen Bildungschancen (der Film zeigt sie bei Vorbereitungen auf die Abiturprüfungen; tatsächlich schloss sie nach dem Erwerb der Hochschulreife noch ein Studium an und wurde schließlich 1993 im Alter von 73 Jahren mit einer erziehungswissenschaftlichen Dissertation über die Industriepädagogik an der Wende vom 19. zum 20. Jahrhundert an der Universität-Gesamthochschule Essen promoviert).

${ }^{35}$ Zur Einrichtung der Trauerfeier und ihres Ablaufes s. Thuk. 2,34,1-7. Die grundlegende Darstellung zu den Epitaphioi und ihrer Bedeutung für die Polis Athen ist LORAUX 1993, neben der besonders auch ZIOLKOWSKI 1981 und PRINZ 1997 zu nennen sind. Für das Ritual selbst und seinen Ablauf s. LORAUX 1993, 45-102.

${ }^{36}$ PRINZ 1997, 19.

37 Thuk. 2,34,6.

${ }^{38}$ Die Beurteilung des Perikles ist in der Forschung aufgrund der Quellenlage höchst kontrovers. Lange Zeit galt dies auch für die Einschätzung der persona des Politikers im Peloponnesischen Krieg, was nicht zuletzt mit gegensätzlichen Interpretationen des Epitaphios zu tun hat. Spätestens mit der minutiösen Untersuchung von WILL 2003 ist jedoch der Nachweis gelungen, dass der Perikles des Peloponnesischen Kriegs einerseits eine in höchstem Maß stilisierte Figur ist und Thukydides ihn andererseits zum Ideal eines Politikers in der Demokratie stilisiert hat. Zu den Fähigkeiten eines Staatsmanns, die Thukydides im Nachruf auf Perikles dingfest macht (Thuk 2,65,5; 8; 9) s. RAAFLAUB 2006, 204 f.

${ }^{39}$ Zur strittigen Frage der Historizität im Einzelnen s. den Überblick bei PRINZ 1997, 96-9; 133 f.
} 


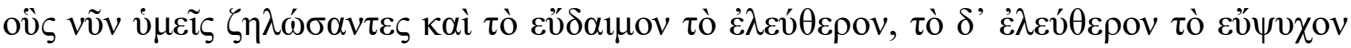

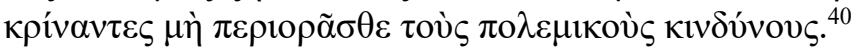

Für das Verständnis der Rede ist die Vergegenwärtigung zweier Zeithorizonte, der Sprecherzeit und der Abfassungszeit, notwendig. Während es im Jahr 431/30 das Ziel der historischen Gestalt Perikles war, die Bürgerschaft für die Verteidigung und den Ausbau des Modells Athen im Peloponnesischen Krieg zu mobilisieren, kam es Thukydides bei der Abfassung etwa im Jahr 400 darauf an, nach dem Verlust der athenischen Hegemonie und des Zusammenbruchs des politischen Systems die Bedingungen für die Wiedererlangung der einstigen Stärke aufzuzeigen. Die Rede, die Thukydides für Perikles schreibt, ist daher nicht nur auf die Durchsetzung von zum Zeitpunkt der Ansprache aktuellen Problemen ausgerichtet. ${ }^{41}$ Über den konkreten Anlass hinaus kristallisiert sich im Duktus und in der Anlage des Epitaphios auch die geschichtspolitische Absicht des Historikers heraus: das Ideal einer spezifischen, auf das Individuum ausgerichteten Lebensform zu rühmen und den potentiell tödlichen Einsatz der Bürger für ein solches Gemeinwesen durch die Erinnerung an die vorbildhaften Leistungen der Bürger in der Geschichte zu motivieren. ${ }^{42}$

\section{Der Streit um Thukydides (1). Die Auslegung von Berthold Beitz}

In Das Geheimnis der Freiheit dient das Thukydides-Zitat als Antwort, mit der Beitz in einem Fernsehinterview im Sommer 1989 die Frage nach seinem Lebensmotto pariert:

„Ich halte es immer noch mit dem Perikles. Das Geheimnis des Glücks ist die Freiheit, das Geheimnis der Freiheit aber ist der Mut.“

In dieser Version ist der originale Satz zweifach verkürzt. Es fehlt sowohl der erste Teil

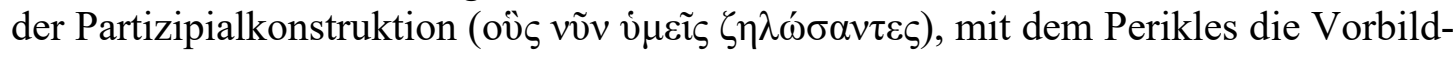
haftigkeit der Gefallenen postuliert, als auch der Hauptsatz mit der Aufforderung an die Bürgersoldaten, sich im Kampfeinsatz dem Feind furchtlos zu entgegenzustellen $(\mu \grave{\eta}$

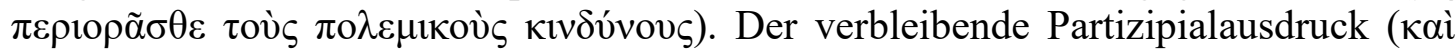

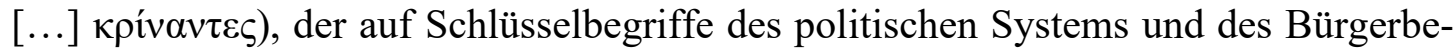

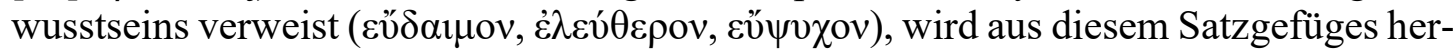
ausgelöst und als Hauptsatz neu konstituiert. Die Parainese des Perikles verwandelt sich dadurch in eine philosophisch grundierte Erkenntnis mit Anspruch auf Allgemeingültigkeit.

\footnotetext{
${ }^{40}$ Das Deutsche entzieht sich einer ebenso prägnanten wie passgenauen Wiedergabe dieses Satzgefüges. Der Übertragung von LANDMANN 2002 ist auf jeden Fall die Version von WEIßENBERGER 2017 vorzuziehen: „Mit ihnen als Vorbildern und in der Erkenntnis, dass Glück in der Freiheit, Freiheit aber in mutiger Zuversicht besteht, lasst euch nicht einschüchtern von den Gefahren des Krieges.“ DE ROMILLY 2009 übersetzt folgendermaßen ins Französische: „Que leur modèle inspire aujourd'hui votre émulation, et, mettant le bonheur dans la liberté, la liberté dans la vaillance, ne regardez pas de trop près aux périls de la guerre." Kongenial in Präzision und Griffigkeit erscheint jedoch die Übertragung von Thomas Hobbes: „In imitation therefore of these men, and placing happiness in liberty, and liberty in valour, be forward to encounter the dangers of war" (HoBBES 1848). Zu den Problemen der lateinischen Übersetzung von Lorenzo Valla s. u. Anm. 43. Es sei darauf hingewiesen, dass die syntaktische Konstruktion und die Interpunktion nicht dazu verleiten dürfen, den Imperativ („lasst euch“, „,ne regardez pas“, „,be forward") versehentlich als Indikativ aufzufassen; hierzu s. u. S. 76.

${ }^{41} \mathrm{Zu}$ diesem häufig unterbelichtet gebliebenen Komplex s. den detaillierten Nachweis der Bezüge zwischen der Rede und der außenpolitischen Situation Athens nach dem ersten Kriegsjahr bei BoswORTH 2000.

${ }^{42}$ Zum ebenfalls längere Zeit umstrittenen Problem der Intentionen des Thukydides s. S. 79.
} 
Diese Adaption des Satzes hält die Beziehung der Termini „Glück“, „Freiheit“ und „Mut“ in der Schwebe. In der Formulierung „Das Geheimnis [...] ist“", die Thukydides” auf Prädikatsnomina beruhende Konstruktion ersetzt, bleibt offen, ob hier Glück, Freiheit und Mut gleichgesetzt werden, ob Freiheit und Mut jeweils nur die Voraussetzung von Glück und Freiheit sind oder ob alle drei Werte einander zwar bedingen, jedoch zumindest teilweise deckungsgleich sind. ${ }^{43}$ Aus der Handlung lässt sich jedoch erschließen, dass Glück für Beitz offenbar identisch mit dem Besitz der Freiheit ist. Unstrittig ist wiederum, dass deren Erwerb und Nutzung von Mut abhängt. In Beitz' Denken fallen also Freiheit und Glück als Ziele menschlichen Handelns zusammen, während der Mut eine notwendige Bedingung für deren Erlangung ist.

Charakteristisch für Beitz' Selbstverständnis ist die Dominanz des positiven, sich in Handlungsmacht manifestierenden Freiheitsbegriffs ${ }^{44}$. Die Bedeutung dieser Form von Freiheit habe ihm, wie er Golo Mann gesteht, die Ohnmachtserfahrung im Nationalsozialismus vorgeführt. Wer die NS-Barbarei erlebt habe, werde immer nach Macht streben, um die Verhältnisse zu beherrschen. Ganz in Übereinstimmung mit dieser Überzeugung tritt er als Verkörperung des Typus des entscheidungskräftigen, unbekümmerten und energischen Managers in Fragen des Unternehmens, aber auch der Politik und des Lebens auf. In sein Freiheitsverständnis passt auch der Auftrag für die Krupp-Biographie, von der er eine Optimierung des Firmenimages erhofft, um die Attraktivität von Fried. Krupp für Investoren zu steigern und dadurch eine drohende finanzielle Schieflage abzuwenden. Mut begreift er dagegen als eine mentale Disposition, die sich auf die Bereitschaft zur Beeinflussung und Gestaltung der Umwelt erstreckt. Als Paradebeispiel dient ihm der Fall der Berliner Mauer, der zur Befreiung der Bevölkerung der DDR von der sozialistischen Diktatur wie zur staatlichen Freiheit Deutschlands durch die Wiedervereinigung geführt habe und erst durch den Widerstand der Ostdeutschen möglich geworden sei. Natürlich sieht er aber auch sich selbst, der als Konzernchef immer wieder scheinbar ausweglosen, letztlich aber entschlossen gemeisterten Situationen ausgesetzt ist und der allen Unwägbarkeiten mit schwungvoller Jovialität begegnet, als Inbegriff von Mut an. Was sich Beitz' Kontrolle jedoch entzieht und sich als Fehlen von negativer Freiheit bemerkbar macht, ist die Vergangenheit. Immer wieder von neuem drängt sie sich renitent in die Gegenwart hinein. Dass sich Beitz nicht bewusst ist, wie sehr er dieser Form von negativer Freiheit bedarf, um seinen Lebensentwurf zu verwirklichen, wie sehr beide Arten von Freiheit aufeinander bezogen sind, darin liegt seine Tragik.

\footnotetext{
${ }^{43}$ Das Verhältnis dieser drei Begriffe zueinander bei Thukydides, das aufgrund der verknappten Formulierung ein - hier allerdings außen vor bleibendes - Problem darstellt, wird in der Thukydides-Literatur zumeist nicht eingehend diskutiert, vielleicht, weil der Sinn (voreilig?) klar zu sein scheint. GOMME 1945, 139 stellt fest: ,this is boldly expressed - ,happiness is freedom, and freedom courage'; more strictly, ,happiness depends on freedom, freedom on courage"'. Ohne Weiteres von einer Identität der Begriffe gehen dagegen KAKRIDIS 1981, 94 und RUSTEN 1989, 171 aus. VALLA 1492/2008 arbeitet zwar eine Deckungsgleichheit zwischen Glück und Freiheit heraus, vergisst darüber aber offensichtlich den Mut ([...] felicitatem existimantes libertatem esse rursus libertatem esse felicitatem nolite [...]). Einleuchtender als eine bedingungslose Gleichsetzung scheint indes Gommes Präzisierung zu sein, die auf eine funktionale Beziehung der Begriffe abhebt. Auch für STEUP/CLASSEN 1914, 117 f. wird der Mut ,zur Grundlage der höchsten Güter erklärt“. Dass auf jeden Fall euäyuxon unabhängig von seinem Selbstwert auch in einem dienenden Verhältnis zu den anderen Werten steht, lässt sich aus Thuk. 5,9,1 erschließen (eben-

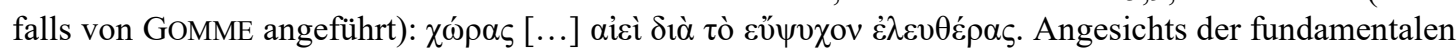
Bedeutung der Freiheit für die politische Kultur Athens (s. u. S. 77 f.) erscheint es auf alle Fälle angebracht, von einer Engführung von Freiheit und Glück bei Thukydides auszugehen.

${ }^{44}$ Die hier gebotenen Ausführungen basieren auf dem zweiseitigen Freiheitsbegriff (positive und negative Freiheit), dem BERLIN 1969 zuletzt besondere Konjunktur verschafft hat.
} 
In einer der depressiven Phasen, in die ihn die Erinnerung stürzt, bittet er Mann aufgrund von dessen Expertise als Verfasser von Gespenstergeschichten in einem nächtlichen Telefonat um Rat. Dessen Empfehlung, sich der Vergangenheit zu stellen - und zwar durch ein Gespräch mit der Erscheinung -, weist er entschieden zurück. Für Beitz bedürfen Gegenwart und Zukunft der Vergangenheit nicht, ja, sie würden vielmehr durch die Erinnerung kontaminiert. Seine Aktionen zur Rettung von Juden gälten zwar als rühmliche Tat, ihre Vergegenwärtigung sei jedoch grauenvoll. So nimmt er zu Manns Verblüffung die Nachricht von der Ernennung zu einem der „Gerechten unter den Völkern“" durch die Gedenkstätte Yad Vashem nur zurückhaltend auf. Lange verschiebt er die Reise dorthin. Für irrelevant hält er auch Manns Bemühungen, im Rahmen der Biographie seine, Beitz', Vergangenheit zu thematisieren, die nach Ansicht des Historikers seine Berufung als Mitglied der Konzernleitung durch den verurteilten Kriegsverbrecher Alfried Krupp beeinflusst haben könnte.

Trotz seines durch die Erinnerung verursachten Unglücks setzt er sich über Manns Feststellung, dass die Vergangenheit nicht auszulöschen sei, unwirsch hinweg. Nur mit Mühe übersteht er 1977 als Mitglied der deutschen Delegation einen Besuch im Konzentrationslager Auschwitz, wo - in die gleiche Richtung wie Mann zielend Helmut Schmidt sowohl allgemein als auch mit Blick auf das deutsch-polnische Verhältnis feststellt, dass ohne Erkenntnis der Vergangenheit keine Zukunft möglich sei. Die Disziplin, die ihm der ebenfalls vom II. Weltkrieg gezeichnete Bundeskanzler mit stoischer Melancholie empfiehlt, bringt ihm keine Hilfe. Andeutungen, ihn treibe die Angst vor der Vergangenheit um, verbittet er sich. Als seine Gattin ihm aber mit dem Hinweis auf seine begrenzten Fähigkeiten zur Kontrolle der Erinnerung vorschlägt, sie sollten endlich gemeinsam die Reise nach Israel antreten, um die Vergangenheit zu bannen, erkennt er darin ein Mittel, seine Freiheit wiederzugewinnen. Doch noch bei der Abreise nach Jerusalem, mit der Das Geheimnis der Freiheit endet, bleibt er bei der Verweigerung einer aktiven Beschäftigung mit seiner Vergangenheit, bleibt er in der, wie Mann es nennt, ,gewählten Stille“.

An Beitz' Zurückdrängung von Nationalsozialismus und Krieg exemplifiziert Das Geheimnis der Freiheit eine bis heute immer wiederkehrende, wenngleich zu keinem Zeitpunkt für die Gesellschaft als Ganze charakteristische Strategie, der sich verschiedene Gruppen mit jeweils spezifischen Zielen bedienten und die mit unterschiedlicher Intensität in allen Phasen der bundesrepublikanischen Erinnerungskultur auftrat. ${ }^{45}$ Für die Intentionen, die Beitz leiten, orientiert sich der Film sichtlich an Verhaltensmustern, die besonders für die 1950er Jahre prägend waren und die auch mit der Handlungszeit des Films vereinbar sind. ${ }^{46}$ Wurden nach dem Zusammenbruch des „Dritten Reichs“ noch eindringliche Diskussionen über das nationalsozialistische Regime geführt, begann in der frühen Bundesrepublik eine Phase des Schweigens, in der konsequent eigene Taten verborgen und allenfalls die Verbrechen des Kollektivs thematisiert wurden. ${ }^{47}$ Stattdessen etablierten Topoi wie Bombenkrieg, Vertreibung, Zerstörung und Kriegsgefangenschaft ein Opfergefühl und brachten die Theorie der „Kollektivunschuld“ (Wolfrum) hervor. ${ }^{48}$ Der Verzicht auf „,bestimmte Formen politi-

\footnotetext{
${ }^{45}$ HAMMERSTEIN 2017, $76 \mathrm{f}$.

${ }^{46}$ S. hierzu v. a. WOLFRUM 2001, 222-5; CONZE 2009, 214-25; HetTling 2000, 367-9 sowie auch FrEI 1996.

${ }^{47}$ Hettling 2000, 367 sowie Graf KielmanSEGG 1989, 17 zur ,abstrakten Natur` der Verurteilung des Nationalsozialismus in der Bevölkerung.

${ }^{48}$ SABROW 2017, 320; HAMMERSTEIN 2017, 73-5.
} 
scher und moralischer Abrechnung mit der Vergangenheit" galt vielerorts als notwendig. ${ }^{49}$ Auch der Neuanfang, der in der Einführung der Demokratie und der Westintegration mitsamt Wiederbewaffnung sichtbar wurde, erleichterte das Aufkommen einer Schlussstrichmentalität. ${ }^{50}$ In den Vordergrund trat das Bemühen um die Gestaltung der Zukunft durch Zurücklassen der Vergangenheit. Zum Ausdruck kommt diese Tendenz in Formeln wie dem von Hermann Lübbe geprägten „kollektiven Beschweigen“ der Traumata $^{51}$ oder einer Form von „Vergangenheitsbewältigung“, die nach Ansicht ihrer Vertreter in einer Überlagerung der Vergangenheit bestehen sollte. ${ }^{52}$

Diese Art der Zukunftsorientierung korrespondiert mit dem Lebensgefühl von Beitz. Er betreibt eine für die frühe Bundesrepublik bezeichnende Strategie der „Vergangenheitsdistanzierung“, ${ }^{53}$ bestehend aus einer Mischung von Schweigen und Verdrängen. Zwar gehört er nicht zu den Tätern, sondern hat vielmehr im Rahmen seiner Möglichkeiten die nationalsozialistische Vernichtungsmaschinerie behindert. Was er beschweigen will, ist nicht persönliches Versagen, sondern die Erinnerung an die Machtlosigkeit, die ihm das nationalsozialistische Gewaltregiment aufgezeigt hat. Aber sein Selbstverständnis und sein Handeln sind auf eine Zukunft fixiert, die für ihn ausschließlich in der Prosperität der Firma Fried. Krupp besteht. Bei der Verfolgung dieses Ziels hemmen ihn keine Sentimentalitäten. Ohne zu zögern, spannt er hochrangige Angehörige des Auswärtigen Amts, die engagierte Vertreter des Regimes gewesen sind, für seine Geschäftsinteressen ein und bemüht sich zielstrebig um eine Beteiligung des wegen Menschenrechtsverstößen in der Kritik stehenden Schahs von Persien am Konzern. Im Sinne dieser pragmatisch-funktionalen Handlungsmaximen instrumentalisiert er auch die Geschichte für seine Zwecke. Für ihn ist die Krupp-Biographie ein PR-Projekt. Welche Vergangenheit aufgerufen werden soll, unterliegt einzig einem Nutzenkalkül, das auf seine unternehmerischen Absichten abgestimmt ist. Darin erschöpft sich nach seinem Verständnis die Zweckmäßigkeit und Wirkmächtigkeit von Geschichte.

Das Zitat aus dem Epitaphios in der von Beitz zur Sentenz verdichteten, von jeder inhaltlichen Konkretion abstrahierten Fassung verleiht dieser ganz der Gegenwart verpflichteten Auffassung von Lebensführung und wirtschaftlicher Praxis Legitimation durch die Überzeugungskraft einer ebenso schlichten wie eindrücklichen Wahrheit, deren Triftigkeit die Person des Perikles verbürgt. Sein Name ist das Synonym für den politischen und kulturellen Aufstieg Athens zu einer Großmacht von welthistorischem Format, assoziiert mit einer optimistischen, entscheidungsstarken und umsichtigen Politik nach innen wie nach außen. In ihr drückt sich ein Glücks- und Freiheitsverständnis aus, dessen Verzicht auf metaphysische Komplikationen und seine Verhaftung in der Gegenwart Beitz' Selbstverständnis als Konzernlenker entspricht und bestärkt. Aus dieser Perspektive, die Freiheit und Glück mit Gestaltungsmacht identifiziert, besitzt die Vergangenheit nicht den Status einer Realität. Die Bedrängungen, die Beitz bei der

\footnotetext{
${ }^{49}$ Graf KielmansegG 1989, 15 f. (Zitat 16).

${ }^{50}$ Graf KiELMANSEGG 1989, 45-7.

${ }^{51}$ LÜBBE 1983, bes. 585-7; hervorzuheben ist, dass für Lübbe das Schweigen nicht mit Verdrängen gleichgesetzt werden darf (588 f.). Zu dieser These und ihrer Geltung s. GRAF KIELMANSEGG 1989, 17 f.; WOLFRUM 2006, 170; HAMMERSTEIN 2017, 72.

${ }^{52}$ Zum Problem dieser Haltung s. SABROW 2017, $323 \mathrm{f}$. Es ist unbedingt festzuhalten, dass der Begriff „Vergangenheitsbewältigung“ vielfältige und auch gegensätzliche Ausprägung kennt und auch eine Bewusstseinsmachung der Vergangenheit bedeuten konnte. Hilfreich hierzu ist die knappe Begriffsgeschichte von DUDEK 1992.

${ }^{53}$ Zur Verwendung dieses für die Erfassung unterschiedlicher Ausprägungen der Nichtthematisierung der Vergangenheit hinreichend weitgefassten Begriffs für die Geschichtskultur der Nachkriegszeit s. SABROW 2017, 319-24.
} 
Erinnerung an den Nationalsozialismus empfindet, und ihre Bekämpfung entziehen sich kategorial den drei tragenden Komponenten seines von Perikles formulierten Lebensmottos: Glück, Freiheit und Mut. Ihm, der bezeichnenderweise ein leidenschaftlicher Bildersammler ist, aber noch nie ein Buch gelesen hat, ist die nichtgegenständliche, virtuelle Entität der Vergangenheit fremd, wenngleich er ihre Präsenz und Wirkung spürt und nicht abzuschütteln vermag.

\section{Der Streit um Thukydides (2). Die Auslegung Golo Manns}

1990, ein Jahr nach dem Interview, das er im Fernsehen verfolgt hat, begegnet Golo Mann Berthold Beitz am Flughafen. Endlich hat sich Beitz entschieden, die ihm 1974 zugesprochene Auszeichnung als „Gerechter unter den Völkern“ in Yad Vashem entgegenzunehmen. Als sich herausstellt, dass ihn die Erscheinung seiner deportierten Sekretärin noch immer verfolgt, lenkt Mann das Gespräch auf Perikles. Schon beim Fernsehauftritt hat es seinen Anstoß erregt, dass Beitz das Zitat aus dem Epitaphios Perikles zuweist, obwohl es tatsächlich von Thukydides stammt. Unter Bezug auf die für das Verständnis der Vergangenheit notwendige Professionalität (,als Historiker“) korrigiert Mann nun Beitz' Übersetzung von damals. Nicht nur weist er ihm die falsche Zuordnung des Zitats nach. Beitz habe außerdem, so zeigt er, den entscheidenden Teil des Satzes unterschlagen. Tatsächlich laute Perikles' Dictum so:

„Indem ihr als das Glück die Freiheit und als Freiheit den Mut anseht, fürchtet ihr euch nicht vor den Gefahren des Krieges.“

Auch diese Fassung des Zitats blendet den Anfang der Konstruktion mit dem Verweis auf die Gefallenen und deren erinnerungswürdigen Leistungen aus, fügt aber die Übersetzung des griechischen Hauptsatzes hinzu, auf den die Erläuterung des Zusammenhangs von Glück, Freiheit und Mut abzielt. Während Beitz den zweiten Teil der Parti-

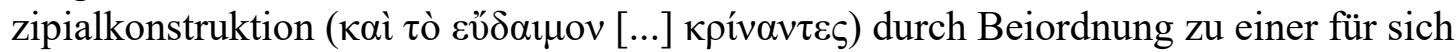
stehenden Sentenz formt (,Das Geheimnis [...] ist [... $]^{6)}$ ), wird sie in Manns Übersetzung mittels Subordination zu einem Modalsatz (,Indem ihr [...] erkennt [... $]^{\text {“) }}$, der faktisch die Voraussetzungen für die im Hauptsatz enthaltenen, mit Notwendigkeit eintretenden Folgen (,habt ihr keine Angst") bestimmt.

Das Selbstverständnis des souveränen Krupp-Managers, der von der Vitalität seines Muts überzeugt ist, erschüttert Mann mit der von ihm belehrend als historisch und sprachlich korrekt apostrophierten Übersetzung im Kern. Die Gefahren des Krieges, die Perikles erwähnt, deutet er als die schreckliche Erinnerung an den Krieg, worunter er offensichtlich nicht furchteinflößende Kampfhandlungen, sondern den Nationalsozialismus und dessen Verbrechen versteht. Wäre Beitz so mutig, wie er selber von sich denkt, könnten ihn - so die bestechende Logik des Modalsatzes - die Schrecken des Krieges unmöglich peinigen. Da ihn aber die Erinnerung an den Nationalsozialismus noch immer quäle, lautet die zwingende Schlussfolgerung, dass es ihm an dem gebotenen Mut fehle. Diese implizite Argumentation, deren Konsequenzen Beitz am Flughafen sofort einsieht, weist nach, dass Beitz' gescheiterte Strategie des Schweigens und Unterdrückens ein Ausdruck von Mutlosigkeit gewesen ist. Zugleich beweist der Satz des Perikles die Richtigkeit von Manns Einsicht, dass Loslassen nur durch Verstehen möglich sei und dass die Gestaltung der Zukunft in Freiheit nicht in einem zwanghaften Präsentismus bestehen könne, sondern der Auseinandersetzung mit der Vergangenheit bedürfe. 
Beitz' Angst spürt Mann von Anfang an. Die periodisch wiederkehrende Erinnerung des Managers deutet er als Kontroll- und Machtverlust eines hypostasierten Strebens nach Freiheit, deren Einschränkung durch die Verdrängung der Vergangenheit unfreiwillig zementiert wird: So sei er stets ein Gefangener seiner Erinnerungen geblieben. Nach Manns Auffassung konstituiert sich die Freiheit nicht nur im Mut bei der Beseitigung von Widerständen, denen sich das Individuum in der Welt gegenübersieht, sondern auch und zunächst beim Umgang mit der eigenen Psyche, vor deren unbefangener Analyse Beitz zurückschreckt. Beitz' nachlässige und entstellende Behandlung des Thukydides-Zitats ist für Mann symptomatisch für dessen selbstzerstörerische Haltung zur Vergangenheit. Dem irrenden Dilettantismus stellt er die von ihm verkörperte Professionalität des Historikers gegenüber. Er demonstriert, dass es erst durch wissenschaftliche Genauigkeit gelinge, ein genaues Verständnis der Vergangenheit zu entwickeln und dadurch Handlungsmöglichkeiten für eine Zukunft zu eröffnen, die sich von emotionalen Zumutungen der Geschichte emanzipiert.

Mit Manns Widerspruch gegen das Verdrängen präsentiert Das Geheimnis der Vergangenheit ein paradigmatisches Beispiel für das erstmals 1959 von Theodor W. Adorno formulierte Konzept der Aufarbeitung der Vergangenheit. ${ }^{54}$ Als Antidot zu einer Schlussstrichmentalität versprach es die Befreiung von der Vergangenheit mit Hilfe von deren Durcharbeitung. Dieser Ansatz wurde durch die rasch zum Schlagwort geronnene Diagnose von der „Unfähigkeit zu trauern“ popularisiert, die Alexander und Margarethe Mitscherlich den Deutschen stellten und die vor den psychischen Schäden durch eine Absonderung der Vergangenheit im Namen bedenkenloser Zukunftsorientierung warnte. ${ }^{55}$ Nachdem eine erste Phase der intensiven Auseinandersetzung mit dem Nationalsozialismus über Teile der politischen Elite, den Eichmann- und den Auschwitz-Prozess, die Debatte um die Verjährung der NS-Verbrechen sowie geschichtswissenschaftliche Kontroversen und maßstabsetzende Publikationen ${ }^{56}$ abgeklungen war, kehrte ab dem Ende der 1970er Jahre die Vergangenheit zurück, als die damals einsetzende Modernitäts- und Wachstumskrise auch eine Identitätskrise erzeugte ${ }^{57}$ Es setzte ein von unterschiedlichen Akteuren und Gruppen von je eigenen politischen Zielen getragener, die gesamte Gesellschaft durchdringender Geschichtsboom ein, der wahlweise als „Heimweh nach Geschichte“, „Flucht in die Geschichte“, „Erinnerungsmanie“ oder „Erbe-Obsession“ etikettiert worden ist. ${ }^{58}$ Auch bedingt durch die aktive Geschichtspolitik von Bundeskanzler Kohl, rückte der Nationalsozialismus ,,in den Mittelpunkt der kulturellen und politischen Debatten“ der Bundesrepublik. ${ }^{59}$ Mit zunehmender zeitlicher Distanz zum „Dritten Reich“ verstärkte sich der Wunsch nach einer Konkretisierung der Erinnerung. ${ }^{60}$ Nicht nur kristallisierte sich in dieser Zeit der gesellschaftliche Konsens heraus, dass allein eine gewissenhafte Aufarbeitung der NS-Verbrechen deren Wiederholung verhindern könne. ${ }^{61}$ Immer wieder warben Inhaber politischer Spitzenämter von Walter Scheel über Helmut Schmidt und

\footnotetext{
${ }^{54}$ ADORNO 1959 (gedruckt 1963). Zur weiteren Begriffsgeschichte s. den Überblick von BECKER 2013, 101-4; zu Adorno VAN LAAK 2000, 18 f. mit Kritik.

${ }^{55}$ Zur These der Mitscherlichs, die nicht in den moralischen und materiellen Verlusten des Krieges, sondern in der gescheiterten Liebe der Deutschen zu Hitler den Anlass für Trauer sahen, s. zusammenfassend FREIMÜLLER 2007, 303-21, bes. 303 f., 316-21.

${ }^{56}$ S. hierzu im Einzelnen HERBERT 2014, 771-3.

${ }^{57}$ Herbert 2014, 1010-22; WOLFrum 2001, 229-34; WIRSCHING 2006, 467-9; 471; 2012, 382.

${ }^{58}$ WOLFRUM 2006, 391-401 (die Zitate 395); HAMMERSTEIN 2017, 137-9.

${ }^{59}$ Herbert 2014, 1016 sowie die umfassende Darstellung von WOLFRUM 1999; WIRSCHING 2006, 477; HAMMERSTEIN 2017, 146-9 mit 311 f. zu Schlussstrichforderungen von konservativer Seite.

60 WIRSCHING 2006, 477.

${ }^{61}$ SABROW 2017, 326.
} 
Helmut Kohl bis zu Richard v. Weizsäcker in eindringlichen, teils vielbeachteten Ansprachen auch für die Einsicht, dass das Individuum ebenso wie die Gesellschaft nur durch die Erinnerung Freiheit und Zukunft gewinnen würden. ${ }^{62}$

Um die Mechanismen der Erinnerung und die im Zeichen der Aufarbeitung gebotenen Anforderungen an den Umgang mit der Vergangenheit zu vermitteln, erweist sich die von Mann vervollständigte Version des Zitats, dessen Hauptsatz Beitz amputiert hat, als ein ideales Instrument. Die Freiheit als Voraussetzung und Bestandteil des Glücks besteht nicht nur in der Fähigkeit zur Gestaltung der Umwelt, sondern auch in der Regulierung der Psyche, zu der auch das Geschichtsbewusstsein gehört. Im Gegensatz zu Beitz zeigt sich in Manns Ausdeutung des komplettierten Perikles-Satzes der Mut nicht allein im entschlossenen Handeln, sondern zuallererst in der Auseinandersetzung des Individuums mit sich selber. Der Negation der Relevanz der Vergangenheit, die Beitz aus Perikles' Satz ableitet, hält Manns Übersetzung das Versprechen mutigen Handelns entgegen, dessen Erfüllung qua Gesetzmäßigkeit eintritt: die Schrecken des Krieges zu bannen. Die Einsicht in die zwingende Verbindung zwischen dem Mut und der Neutralisierung des Schreckens offenbart die Ignoranz der Selbsteinschätzung von Beitz und die Fehlerhaftigkeit seiner Interpretation. Erforderlich ist Mut daher nicht nur im Hinblick auf die Gegenwart, sondern auch auf die Vergangenheit. Wenn die Schrecken des Krieges nur durch Mut zu bändigen sind, trifft diese Erkenntnis seiner Ansicht nach nicht nur auf bevorstehende militärische Auseinandersetzungen zu, sondern besonders auf jene Kämpfe, deren Realität sich allein im Medium der Erinnerung manifestiert.

Die vervollständigte Fassung des Zitats entlarvt Beitz' Verhältnis zur Vergangenheit, aus der sich dessen Selbstbewusstsein speist, mit der Wirkmächtigkeit der von

\footnotetext{
${ }^{62}$ Zum Kontext der Reden und einer Einordnung s. HAMMERSTEIN 2017, 247; 249; 251; 314 f.; 315 f. $\mathrm{m}$. w. Lit. Zum 30. Jahrestag des Kriegsendes stellte sich Scheel einer Schlussstrichmentalität mit der Forderung entgegen, ,diese dunkle Phase unserer Geschichte in unser Bewußtsein auf[zu]nehmen und sie nicht [zu] verdrängen $(177 ; 180)$, und zwar nicht nur aus pragmatischen Gründen der Innen- und Außenpolitik (passim), sondern weil ,,alle Worte von nationaler Würde, von Selbstachtung hohl [bleiben], wenn wir nicht das ganze oft genug drückende Gewicht unserer Geschichte auf uns nehmen. Es geht um unser Verhältnis zu uns selbst“" (180). SCHMIDT 1975 betonte dagegen zum gleichen Anlass vor allem die Lehren aus der Geschichte (für die Konstitution eines „demokratischen und sozialen Rechtsstaat[s]“ [13 f.] und dessen Bewahrung [bes. 17] sowie die Aussöhnung mit früheren Gegnern [18 f.]). Noch deutlicher hoben zehn Jahre später Kohl und v. Weizsäcker die Bedeutung der Erinnerung und die Auseinandersetzung für das Geschichtsbewusstsein hervor. Für KOHL 1985 war die Erinnerung einerseits ein Appell, die „Verantwortung der Geschichte anzunehmen“, und eine „Lektion“, die einer Wiederholung der Verbrechen vorbeugen solle (16). Andererseits diente sie als „Mahnung“ zur Wahrhaftigkeit (5 mit $13 \mathrm{f}$.). Daneben habe die Erinnerung aber auch unmittelbare Auswirkungen auf jeden Einzelnen, wie er mit dem Zitat eines ,,jüdischen Mystikers aus dem Anfang des 18. Jahrhunderts“ bekräftigte, dem er in Yad Vashem begegnet sei und mit dem er auch die Rede überschreibt: „Das Geheimnis der Erlösung heißt Erinnerung“ (18). Explizit unter Berufung auch auf einen psychologisch gefärbten Freiheitsbegriff betonte V. WEIZSÄCKER 1985 die Bedeutung der Erinnerung, wenn er feststellt, der 08. Mai sei „zugleich ein Tag des Nachdenkens über den Gang unserer Geschichte. Je ehrlicher wir ihn begehen, desto freier sind wir, uns seinen Folgen verantwortlich zu stellen“" (1). Mit Blick auf das Geschichtsbewusstsein hielt er fest, „Erinnern heißt, eines Geschehens so ehrlich und rein zu gedenken, daß es zu einem Teil des eigenen Innern wird“" (2). Mit dem gleichen Zitat wie Kohl zielte er auf die ,Lebenswichtigkeit‘ des Erinnerns und die Notwendigkeit zur ,Annahme der Geschichte', während er sich zugleich gegen die Versuche wandte, die „Vergangenheit zu bewältigen“ (6).

Die Kerngedanken der Reden sind hier ausführlich im Wortlaut wiedergegeben, weil sie belegen, wie präsent in den offiziellen, das kommunikative Gedächtnis prägenden und insofern auf die Gesellschaft einwirkenden Stellungnahmen zur Bedeutung der Auseinandersetzung mit dem Nationalsozialismus die Relevanz der Erinnerung für das Geschichtsbewusstsein und damit die Psyche sowie die Gestaltung der innen- und außenpolitischen Verhältnisse ist, die bei den Verfechtern des Verdrängens und Schweigens oder des Bewältigens der Vergangenheit durch Abschließen in Frage steht.
} 
diesem selbst angerufenen Autorität als Fehleinschätzung eines Dilettanten, der ein naives Geschichtsverständnis besitzt. Perikles' Satz, so wie ihn der professionelle Historiker Mann übersetzt, bestätigt, dass Beitz mit seinem Bemühen um Verdrängung einer Illusion anhängt. In dieser Form des Dictums ist angelegt, was die führenden Vertreter der Bundesrepublik in den 1970er und 1980er Jahren, gefolgt von einem Großteil der Bevölkerung, unter dem Eindruck der Wiederkehr der Geschichte und angesichts der Dialektik von Erinnerung, Freiheit und Zukunft als Handlungsmaxime begriffen. Ihnen verschafft Perikles durch seine Zeitlosigkeit seiner Feststellung Legitimation.

\section{Golo Mann, Thukydides und Anspruch der Historizität}

Die Interpretation Golo Manns, der einen in der Professionalität des Historikers begründeten Exklusivitätsanspruch auf den korrekten Umgang mit der Vergangenheit erhebt und aus dieser Haltung heraus Beitz Fahrlässigkeit attestiert, ist indes selbst nur durch eine Abweichung von Thukydides möglich: durch eine Manipulation des Wortlauts und eine damit verbundene Neudeutung des Zitats.

Ausschlaggebend für Manns Aneignung ist, dass er eine sinnverändernde Modifikation am Prädikat des Hauptsatzes vornimmt: Er verwandelt den Imperativ ( $\mu$ ì $\pi \varepsilon \rho 10 \rho \tilde{\alpha} \sigma \theta \varepsilon-$,„,habt keine Furcht!“) in einen Indikativ (,fürchtet ihr euch nicht"“). ${ }^{63}$ Durch diese Veränderung des Modus verschieben sich der inhaltliche Schwerpunkt des Satzes und die Bezüge zwischen der Partizipialkonstruktion und dem Hauptsatz. Die Einsicht in die Tatsache, dass Glück in der Freiheit liege und Freiheit von Mut abhänge, hat bei Perikles keinen automatischen Einfluss auf die Wahrnehmung, bewirkt keine Abwesenheit oder den Verlust von Furcht. Vielmehr dient sie der psychologischen Ermöglichung eines Verhaltens, die Bereitschaft zum mutigen Einsatz im Krieg. Die notwendig eintretende Konsequenz, die Manns Übersetzung erzeugt, ist im Original eine Parainese.

Die für Manns Intention essentielle Veränderung illuminiert weitreichende Differenzen zwischen den Problemen der bundesrepublikanischen Politik-, Gesellschaftsund Mentalitätsgeschichte und der politischen Situation Athens im und nach dem Peloponnesischen Krieg, vor deren Hintergrund Perikles' Rede, aber auch ihre Funktion im Geschichtswerk des Thukydides ihre Bedeutung entfaltet. ${ }^{64}$

\footnotetext{
${ }^{63}$ Wegen der überragenden Bedeutung dieses Eingriffs in den Text sei explizit betont: Es besteht kein Zweifel, dass trotz Formengleichheit im Griechischen (KÜHNER/BLASS 1892, 135-7) kein Indikativ oder Konjunktiv Präsens, sondern ein Imperativ vorliegt (KüHNER/GERTH 1898, 189-94).

${ }^{64}$ Die Literatur zum Epitaphios ist inzwischen unübersehbar. Neben der dominierenden Sicht, der auch die hier angestellten Überlegungen folgen, dass Thukydides durch die Figur des Perikles ein positives Bild des Modells Athen konstruiert, existieren auch Stimmen, die auf freiheitsbegrenzende, teils auch identitäre Bezüge zwischen Bürgern und Polis aufmerksam machen und daher in der Rede entweder das Ideal eines autoritären, wenn nicht gar proto-faschistischen Gemeinwesens erblicken oder aber angesichts des von Thukydides dargestellten Niedergangs Athens nach Perikles' Tod, der Widersprüche zwischen Perikles' Ausführungen und der Realität sowie der geschilderten Exzesse der Demokratie von einer Parodie sprechen. Diese im Detail sehr umfassend begründeten Ansätze repräsentieren die wirkmächtigen Untersuchungen von STRASBURGER 1954 und 1958 und LANDMANN 1974, FLASHAR 1969 und 1975 und MACLEOD 1996. Überzeugende und im Grundsatz noch heute gültige Argumente, die auch die hier vorgelegte Deutung des Epitaphios bestimmen, hat GAISER 1975 gegen die in der deutschsprachigen Forschung angestellten Thesen vorgebracht und dabei plausibel auf deren Beeinflussung durch die Geschichte des 20. Jahrhunderts und das Zeitalter der totalitären Ideologien verwiesen (17-20). Stellt man diese Zeitgebundenheit in Rechnung, wird das im Folgenden skizzierte Verhältnis zwischen dem Indivi-
} 
Chronologisch liegen die „Gefahren des Krieges“ in zwei entgegengesetzten Richtungen eines imaginären Zeitstrahls. Während Golo Mann und Berthold Beitz dabei an die Vergangenheit denken, den zur Zeit der Filmhandlung etwa 40 Jahren zurückliegenden II. Weltkrieg sowie dessen Implikationen, handelt es sich bei Perikles um in der Zukunft liegende Herausforderungen, die Feldzüge, in denen Athen seine Autarkie verteidigt. Mit dieser Differenz sind auch substanzielle Unterschiede der Gefahren verbunden. Mann und Beitz suchen nach der Linderung eines durch die Erinnerung versursachten Traumas - Perikles' Anliegen ist es, die Athener Bürger zur Bewältigung militärischer Herausforderungen und zu Kampfeinsätzen zu motivieren. Ist diese Form mutigen Verhaltens der Athener nach außen und gegen andere gerichtet, benötigen die Deutschen Mut, um im Ringen gegen sich selbst und ihre eigene psychische Disposition anzutreten.

Die Ursache für die Gegensätze zwischen der Absicht des Perikles und den Zielen seiner Interpreten liegt in den von Grund auf unterschiedlichen Situationen, in denen sich Athen und die Bundesrepublik Deutschland der 1970er und 1980er Jahre befinden: hier das erfolgreiche Aufstiegs- und Modernisierungsmodell der idealen Polis Athen, die sich auf dem Höhepunkt ihrer Geschichte befindet, dort das infolge des Nationalsozialismus äußerlich geteilte, innerlich durch ein welthistorisch einmaliges Maß an Schuld moralisch tief korrumpierte Deutschland. Perikles strebt eine Fortschreibung der Vergangenheit durch die Gegenwart hinweg in die Zukunft an, ${ }^{65}$ Beitz und Mann ringen um die Bewältigung einer Vergangenheit, in Abgrenzung zu der erst die Zukunft möglich wird. Die Unterschiede in der Haltung zur Vergangenheit demonstriert auch, dass sowohl Beitz als auch Mann den ersten Teil der Partizipialkonstruktion des Zitats weglassen, der zur Orientierung an den Leistungen der Vorfahren auffordert und Perikles' Absicht zum Ausdruck bringt, die Kontinuität in der Geschichte Athens fortzuschreiben.

Auch hinsichtlich der Konkretisierung der beiden eng aufeinander bezogenen Werte Glück und Freiheit differieren Original und Übersetzungen. Zur Zeit der Filmhandlung war die Bundesrepublik Deutschland durch Demokratisierung, Westintegration und wirtschaftlichen Aufschwung ungeachtet der nationalen Teilung und der noch bestehenden Begrenzungen der Souveränität ein Gemeinwesen mit historisch bislang einmaligen Möglichkeiten für die individuelle Entfaltung jedes Einzelnen. Was als Fehlen an Freiheitlichkeit empfunden werden konnte und worauf auf dem Feld der Erinnerungspolitik immer wieder hingewiesen wurde, war die teils unbewältigte - und auch immer wieder von Neuem zu bewältigende - nationalsozialistische Vergangenheit mit ihren vielfältigen Einflüssen, die bis tief in das Alltagsleben hineinragten. Während sich für Perikles das Problem von Glück und Freiheit an der Frage der politischen Ordnung oder der gesellschaftlichen Kultur festmacht, zeigt sich an Beitz und Mann, die als Filmfiguren zumindest Teile der Gesellschaft repräsentieren, dass die Wahrnehmung der äußeren Lebenschancen einer inneren Freiheit bedarf, die im Umgang mit eigenen Erfahrungen, in der Auseinandersetzung mit der Vergangenheit erzeugt wird.

\footnotetext{
duum und der Polis, das gerade Flashar problematisiert hat, seine Anstößigkeit verlieren. Zu einer adäquaten historischen und zumal kulturgeschichtlichen Einordnung s. auch besonders die sogleich zitierten Untersuchungen zum Mut als Bürgertugend.

Zum Epitaphios als Ideal bei Thukydides s. bspw. GAISER 1975, 19 f; 23-7; 51 (mit Betonung des utopischen Gehalts); LORAUX 1993, 128-31; 133-6; RAAFLAUB 2006, 192; 196 f.; 2013, 12 f. Eine Übersicht der Topoi in den Gefallenenreden bieten ZIOLKOWSKI 1981, 100-37, für Thukydides 134-7 sowie LORAUX 1993, passim.

${ }^{65}$ Die Leistungen der Vergangenheit referiert Thuk. 2,36. Zum Wettkampf der Gegenwart mit der Ver-

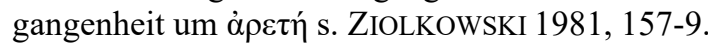


Umfassender als in Manns Übersetzung ist Perikles' Verständnis von Freiheit und Glück. Seiner Vorstellung nach garantiert das Athener Modell eine vollständige Autarkie. ${ }^{66}$ Nach außen gerichtet schwebt ihm dabei eine unbegrenzte, mit einem hegemonialen Anspruch verbundene Souveränität vor. Sie bildet die Voraussetzung für die innere Freiheit zur autonomen Lebensführung. ${ }^{67}$ Die Fähigkeit, ein dem eigenen Willen gemäßes Leben zu führen, macht Risikofreude und Dynamik zu zentralen Eigenschaften der Polis Athens wie ihrer Bürger. ${ }^{68}$ Dieses innenpolitische Ideal, das zwischen dem „Individuum als Privatperson und dem Individuum als Bürger“ unterscheidet, schließt eine private und eine politische Komponente ein, die sich gegenseitig bedingen. ${ }^{69}$ Die Stadt besitzt jedoch nicht nur eine funktionale Bedeutung für den Einzelnen als Garantin seiner Freiheit, wie Perikles betont, sondern - ,ihr sollt Liebhaber Athens werden ${ }^{670}$ - der Einsatz für sie besitzt auch eine identitätsstiftende Bedeutung, die über das Leben des Individuums und dessen praktisch verstandenen, auf die eigene Existenz bezogenen Ziele hinausreicht. ${ }^{71}$ Die Stadt soll nicht nur aus Nützlichkeitserwägungen verteidigt werden, sondern im militärischen Einsatz für die Polis realisiert sich auch ein aristokratischer Wertekodex, der die Demokratie vitalisiert. ${ }^{72}$ Die Möglichkeit jedes Bürgers zum Ausleben seiner Persönlichkeit ist in diesem Freiheitskonzept nicht von der Bindung an die Gesellschaft abzukoppeln. ${ }^{73}$

Der auf ein eher innerliches Freiheitsverständnis beschränkten Deutung des Zitats steht somit ein umfassendes Freiheits- und Glückskonzept im Original gegenüber, das allerdings nicht auf psychologische Tiefenschichten ausgreift. Erklärbar ist auch diese unterschiedliche Akzentuierung aus den jeweiligen historischen Kontexten. Während in der Bundesrepublik alle äußeren Voraussetzungen für ein Leben in Freiheit und ein individuelles Glücksstreben durch die ökonomische und politische Ordnung erfüllt waren, die Vergangenheit aber eine Belastung darstellen konnte, deren Folgen alle günstigen materiellen Bedingungen zu konterkarieren in der Lage waren, so stand im Peloponnesischen Krieg das Athener Modell mit seiner Verschränkung von politischer und privater Freiheit als Bedingung und Eigenschaft von Glück als Ganzes zur Disposition. Nicht vom Ringen mit sich selbst hing die Freiheit der Bürger Athens ab, sondern von ihrer militärischen Schlagkraft. Wie zutreffend die Überlegungen des Perikles waren, erwies sich im Friedenschluss, als die Demokratie und von einer Oligarchie abgelöst wurde.

Angesichts der konstitutiven Stellung der inneren wie äußeren Freiheit in der politischen Kultur Athens war Mut denn auch eine für das athenische Bürgerbewusstsein zentrale Tugend. ${ }^{74}$ Die unbeschränkte Freiheit nach außen sowie die Autarkie des

\footnotetext{
${ }^{66}$ Zur Polis Athen als Lebensform s. bes. Thuk. 2,37-41.

${ }^{67}$ Zur Verbindung von innerer und äußerer Freiheit s. bes. RAAFLAUB 2004, 184; 186.

${ }^{68}$ Hierzu ausführlich OBER 2015, 298-300.

${ }^{69} \mathrm{Zu}$ diesem Komplex s. MEIER 1980, 260; BLEICKEN 1995, 366-70; HANSEN 1995, 466-81 (das Zitat 480); BRINGMANN 2019, 61-4. Für vergleichbare Ansätze im politischen Diskurs Athens s. HANSEN 1995, 474 f. mit Verweis auf Aristot. pol. 1317a40-b17 sowie Hdt. 3,82,2 f.; Thuk. 2,37,2; 7,69,2; Lys. 26,5. S. ferner RUSTEN 1989, 154 über die Fähigkeit der Athener, ihre privaten Angelegenheiten im Zusammenhang mit öffentlichen Themen zu denken.

70 Thuk. 2,43,1.

${ }^{71}$ S. hierzu MACLEOD 1996, 152 und PRINZ 1997, 106; $115 \mathrm{f}$.

${ }^{72}$ RUSTEN 1986, 71 nach LORAUX 1993 und KAGAN 1990, 150

${ }^{73}$ Zum Text s. RUSTEN 1986 und RAAFLAUB 2004, 185 und 230 f. sowie zur politischen Kultur Athens des weiteren BLEICKEN 1995, 366 f.; 369 und jetzt auch BRINGMANN 2019, 61-4; 77.

${ }^{74}$ Für Literatur zum Mut s. BALOT 2004, 407, Anm. 1. Weißenberger übersetzt das anstelle von ỏ $\rho \varepsilon \tau \eta ́$

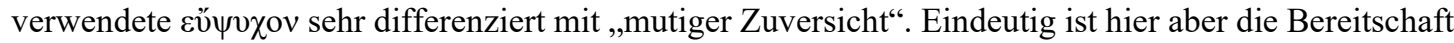
zum Kampf und die Inkaufnahme des Todes in der Schlacht gemeint, die mit „Mut“ wiederzugeben legitim sein sollte; s. in diesem militärisch markierten Sinne auch Thuk. 2,39,1 selbst sowie ferner bspw.
} 
Individuums hing von der Fähigkeit der Polis zur Projektion hegemonialer Macht ab. Von allen Lebensformen, die in der Polis realisiert werden können, hegt Perikles eine deutliche Präferenz für ein militärisch imprägniertes Bürgerverständnis. ${ }^{75}$ Nur durch die Bereitschaft zur Aufopferung für die Stadt ist das Ideal der Autarkie zu verwirklichen. ${ }^{76}$ Der Tod in der Schlacht gilt daher für ihn als Ausweis höchster Tugendhaftigkeit, ${ }^{77}$ die Anschuldigung von Feigheit dagegen als tiefe Schmach, ${ }^{78}$ wie Perikles' Anrufung der sinn- und orientierungsstiftenden Opferbereitschaft der Vorfahren und der im ersten Kriegsjahr Gefallenen unterstreicht. Für Mann bedeutet Mut hingegen die Bereitschaft zur Konfrontation mit einer dunklen Vergangenheit. Nicht um eine Demonstration von Stärke geht es ihm, sondern im Gegenteil um die Überwindung von Schwäche. Zwar soll auch diese Form von Mut zu Freiheit und Glück führen. Nicht gegen einen äußeren Gegner wird diese Auseinandersetzung geführt, sondern gegen das eigene Bewusstsein, das sich paradoxerweise gegen die Erlangung von Freiheit sperrt.

Problematisch war allerdings auch die politische Situation, in der Thukydides sein Geschichtswerk verfasste. Durch die Niederlage im Peloponnesischen Krieg hatte die Polis ihre Autarkie sowohl nach außen (durch den Verlust ihres Herrschaftsbereiches und -spielraums) als auch nach innen (durch den Oktroi einer von Sparta gestützten Oligarchie) vollständig eingebüßt. Thukydides deckt in seiner historischen Darstellung zahlreiche systemimmanente, das perikleische Ideal konterkarierende Schwächen des Athener Modells auf. ${ }^{79}$ Für das Regieren in einer demokratischen Polis bildet Perikles jedoch für ihn das orientierungsstiftende Vorbild. Dass nach seinem Tod die Rationalität und Vernunft, die ihn und seine Politik bestimmt hatten, gegen Hybris und Demagogie eingetauscht wurden - so sieht es jedenfalls Thukydides -, trug wesentlich zum Verlust des Krieges bei. Insofern ging es für Thukydides bei der Gestaltung der Rede des Perikles am Ausgang des 5. Jahrhunderts weniger um das Plädoyer für die Fortsetzung einer erfolgreichen Entwicklung, als um die Rückkehr oder die Wiederbelebung verschütteter Ideale ${ }^{80}$ - eine Rückbesinnung, die sich in ihrem Bekenntnis zur Vergangenheit, aber auch von der Gesellschaft der Bundesrepublik und ihrer Auseinandersetzung mit den nationalsozialistischen Verbrechen unterschied.

Angesichts der Vehemenz, mit der Mann im Film die Deutungshoheit der Geschichtswissenschaft verficht, stellt sich die Frage, ob das Zitat nicht auch im originalen Wortlaut, ohne Veränderung des Modus des Hauptsatzprädikats, den ihm zugewiesenen Zweck hätte erfüllen können. Manns Ziel ist es, anhand des von Beitz selbst als Lebensmotto angesehenen Zitats einen performativen Widerspruch aufzudecken, der ein defizitäres Selbstverständnis und eine fehlerhafte Kenntnis der menschlichen

Aischyl. Pers. 394; Eur. Rhes. 510 f. und Xen. hipp. 8,21. Zu den im Epitaphios angerissenen Lebensweisen und Thukydides' Favorisierung des Militärischen s. RUSTEN 1985, 14 f.; 18 f. sowie 1989, 152 f. 75 Thuk. 2,42,4 mit BALOT 2009, 56-63. Eine Diskussion zu Perikles' Darstellung bietet RUSTEN 1986, 61.

${ }^{76}$ GAISER 1975, 27; 35; RUSTEN 1986, 58; LORAUX 1993, 145-64. Zu den an Sparta erinnernden „kommunitaristischen“ Elementen der politischen Kultur Athens s. OBER 2010, 72-8, bes. 74 mit Thuk. 2,39,1 f. und 40,2 f.

${ }^{77}$ S. auch Thuk. 2,42,2; 43,2. Vgl. hierzu RUSTEN 1986, 71 (mit LORAUX); 73 f. und YoshitAKE 2010 sowie ferner PRITCHARD 2010B, $14 \mathrm{f}$; $33 \mathrm{f}$.

${ }^{78}$ RoISMAN 2005, 65-7; 105 f.; 111; PRITCHARd 2010B, 32 f.; RUSTEN 1989, 171 zu Thuk. 2,43,4, mit 43,1 und $1,84,3$.

${ }^{79}$ Hierzu eindringlich MACLEOD 1996, 150 f. sowie jetzt RAAFLAUB 2006, 192; 197, die belegen, wie Perikles' Darstellung der Außenpolitik der Realität widerspricht und wie Thukydides selbst unmittelbar im Anschluss an den Epitaphios mit der Schilderung der Pest und dem Zerfall der Zivilität demonstriert, wie fragil das Ideal des perikleischen Athen in seiner Hochphase gewesen sei.

${ }^{80}$ Zum visionären Gehalt der Athen-Darstellung und deren Bezug zur Realität s. bes. die grundsätzlichen Ausführungen von GAISER 1975, 51-5. 
Natur belegt. In seiner Übersetzung ist - wie dargestellt - Beitz' Anspruch, mutig zu sein, unvereinbar mit der destruktiven Macht, die gleichzeitig die Vergangenheit über ihn ausübt. Damit erweist sich die von Beitz als Ausdruck des Muts verstandene und hartnäckig von ihm vertretene Strategie des Verdrängens als wirkungslos. Aus diesem Zusammenhang lässt sich plausibel das Erinnern, das Mann propagiert, als adäquates Mittel im Umgang mit der Vergangenheit herleiten. Dem Original fehlt eine solche kausale Verknüpfung von Mut und Erinnern. Mit Perikles' Appell, keine Furcht vor den Schrecken des Krieges zu hegen, ließe sich sogar das Verdrängen rechtfertigen, wenn man dies als Ausweis von Mut begreifen möchte. Keine Angst zu haben, bedeutet bei Mann die Konfrontation mit der Vergangenheit, nicht den Mut zur Unterdrückung oder das Verschweigen von Erinnerungen. Für die Botschaft des Films war daher eine Änderung des Wortlauts des Thukydides notwendig.

\section{Berthold Beitz als Teil der Rezeptionsgeschichte des Thukydides}

Warum Zahavi dem Thukydides-Zitat überhaupt eine integrale Funktion für den Plot zuwies, hat einen außergewöhnlichen geschichtskulturellen Hintergrund. Um eine willkürliche künstlerische Entscheidung handelt es sich nicht. Schon seit längerem ist der Perikles-Satz mit der Biographie und dem Nachleben von Beitz in einer komplexen Rezeptionsgeschichte zwischen autobiographischer Deutung und Geschichtspolitik verbunden. Beitz selbst sprach erstmals für ein prominent aufgemachtes Interview, das in der Wochenendausgabe der Süddeutschen Zeitung vom 01./02. Februar 2008 erschien, flankiert vom Abdruck einiger Briefe von Überlebenden aus Boryslaw, öffentlich über seine Rettungsaktionen. ${ }^{81}$ Der Anlass dürfte nicht nur sein bevorstehender 95. Geburtstag gewesen sein, sondern auch die Auszeichnung seiner Ehefrau als „Gerechte unter den Völkern“, die ihr 35 Jahre nach ihrem Gatten zuteil wurde. Geführt wurde das Gespräch von Joachim Käppner, einem Redakteur der Zeitung, der zwei Jahre später eine Biographie von Beitz publizierte. Die Redaktion stellte das Gespräch unter die Überschrift „Berthold Beitz über Freiheit“, wobei der Begriff „Freiheit“" durch das Schriftbild wie der eigentliche Titel auf den Betrachter wirken kann.

Sein Selbstverständnis erläutert Beitz bereits zu Beginn des Gesprächs im Zusammenhang mit der Frage, was den „Ausschlag“ für seine Rettungstaten gegeben habe:

„Ich habe aber gar nicht viel nachgedacht, als ich versuchte, so viele Juden wie möglich für meinen Betrieb zu reklamieren und so zu retten. Nein, ich habe darüber eigentlich gar nicht nachgedacht. Ich habe spontan gehandelt, aus dem Gefühl heraus. Ich musste es einfach tun. [...] Man muss im richtigen Moment einfach handeln. Wenn ich viel nachgedacht hätte, hätte ich es vielleicht gar nicht gewagt. Ich bin vom Typ her immer ein Einzelgänger gewesen. Es kam darauf an, den Mut zu haben und zu entscheiden. Perikles, der vor 2500 Jahren Athen führte, hat gesagt: Das Geheimnis des Glücks ist die Freiheit, und das Geheimnis der Freiheit ist der Mut. “82

Im Mittelpunkt von Beitz' Antwort steht die für sein Handeln notwendige Entschlusskraft, die von äußeren Begrenzungen ganz und gar unabhängig ist. Untrennbar ist sie

\footnotetext{
${ }^{81}$ BEITZ 2008A. Die Briefe wurden bereits am Vortag, dem 01.02.2008, in der Onlineausgabe der SZ abgedruckt (BRIEFE AN BEITZ 2008), bemerkenswerterweise im Wirtschaftsteil. Auch das Interview wurde hier schon vor der Druckausgabe publiziert (BEITZ 2008B). Welche Bedeutung die Zeitung dem Gespräch beimaß, wird auch daran deutlich, dass das Gespräch durch einen Aufmacher inklusive Portraitphoto eingeleitet wird (S. 1).

${ }^{82}$ Ebd.
} 
mit Mut verbunden, vielleicht sogar mit ihm identisch. Für Beitz ermöglicht er rasche und spontane Entscheidungen; weder verzögere noch behindere er Handlungsimpulse mit komplexen Folgenabwägungen. Situationsadäquate Handlungsfähigkeit - „im richtigen Moment" - besitzt für ihn trotz womöglich unzureichender Kenntnis der Lage oberste Priorität. Dezision zieht Beitz der Reflexion vor. Folgerichtig schreibt er das Zitat aus dem Epitaphios nicht dem Historiker Thukydides, sondern dem Politiker Perikles zu, dessen Dictum durch sein Wirken als Leiter der athenischen Politik und seinen Erfolg legitimiert ist. Beitz' Motiv, seinen jüdischen Mitarbeitern Schutz und Zuflucht zu gewähren, lässt sich aus seinem (im Interview allerdings nicht klar bestimmten) Freiheitsverständnis ableiten, das aus einer individuellen, gefühlsmäßigen Einsicht in das ethisch Richtige sowie der inneren Unabhängigkeit, Widerstände zu überwinden, besteht. Dass Beitz ein Leben als Glück empfindet, das auf der Durchsetzung seines Freiheitsverständnisses und auf Mut in Form von Entscheidungskraft gründet, spricht er nicht wörtlich aus, aber legt seine Berufung auf Perikles nahe.

Beitz' anlassbezogene autobiographische Deutung im journalistischen Format hat Joachim Käppner für seine eigene, allerdings autorisierte Interpretation des Lebens des Managers aufgegriffen und durch seine erstmals 2010 erschienene Biographie im kulturellen Gedächtnis zu verankern gesucht. ${ }^{83}$ An das Interview anknüpfend, stellt er hier Beitz' gesamtes privates und berufliches Leben unter das Leitmotiv der Freiheit, die Ausdruck einer „Lebenseinstellung ${ }^{648}$, eines von der Jugend an bemerkbaren Strebens nach Selbstbestimmung, gewesen sei. Im Zeichen dieser Unabhängigkeit gelangte er Käppners Narration zufolge aus der pommerschen Provinz in die Großstadt Hamburg, wechselte er unerwartet von einer gerade eingenommenen Spitzenposition beim Iduna-Konzern zu Fried. Krupp, unternahm er zum Zorn des Bundeskanzlers Adenauer diplomatische Initiativen im Zeichen einer Entspannungspolitik, schlug dann den ihm von der sozialliberalen Bundesregierung angebotenen Botschafterposten in Moskau aus, betätigte sich als Wissenschaftsförderer, Mäzen und Sportfunktionär und bestimmte mit Neigung zu unkonventionellen Entscheidungen insgesamt über annähernd 60 Jahre in unterschiedlichen Ämtern die Entwicklung von Fried. Krupp bis zu seinem Tod ganz wesentlich mit. ${ }^{85}$

Mit ,große[r] innere[r] Freiheit", begleitet von seltenem Willen und Mut, erklärt Käppner denn auch Beitz' Bereitschaft, „sich dem Mordapparat entgegenzustellen“86. Das Schlusskapitel der Biographie bezieht sich dann unter der Überschrift „Das Geheimnis der Freiheit" ganz unmittelbar auf den Epitaphios und nimmt das Zitat als Grundlage einer Passage, die Beitz' Charakter definiert:

„Auf Berthold Beitz passt dieser Satz genau. Sein Lebensweg zeigt, was ein Mensch erreichen kann, der die Freiheit des Handelns mit Mut und Verantwortung nutzt. Und wie er trotz aller Mühen ein glücklicher Mensch werden kann. Doch, einzelne Menschen können die Welt verändern. Jedenfalls ein Stück weit.“"87

Käppners Bilanz entspricht unverkennbar Beitz' Selbstsicht. Gleichzeitig fügt sie neue Elemente in dessen Ausdeutung von Perikles' Satz ein. Die ethische Bindung der Frei-

\footnotetext{
${ }^{83}$ Dass die Biographie autorisiert war, wurde erstmal 2013 ersichtlich, als KÄPPNER, dessen Darstellung von der Kritik als übertrieben wohlwollend aufgefasst wurde, diesen Umstand im überarbeiteten Vorwort zur Taschenbuchausgabe mitteilte $(2013,22)$.

${ }^{84}$ KÄPPNER 2010, 159.

${ }^{85}$ KÄPPNER 2010, 153; 159; 381 (zum Kniefall in Warschau von Bundeskanzler Willy Brandt, den Beitz für diese Geste bewunderte).

${ }^{86}$ KÄPPNER 2010, 19 aber auch 101.

${ }^{87}$ KÄPPNER 2010, 528.
} 
heit, die Beitz intuitiv begriff, konkretisiert Käppner, indem er eine humanistisch konnotierte Verpflichtung aus Beitz' exemplarischem Leben ableitet. In einer über das handelnde Individuum hinausgreifenden Perspektive billigt er dem perikleischen Handlungsideal ein allumfassendes Transformationspotential zu, das dem Menschen innewohne. Die Attraktivität des herausfordernden (,trotz aller Mühen“) moralischen Appells unterstreicht er mit der Erwähnung des Glücks, das für ihn im Gegensatz zu Perikles allerdings nicht das Telos des Handelns zu bilden scheint.

Fünf Jahre nach der Veröffentlichung des Interviews und drei Jahre nach dem Erscheinen der ersten Auflage der Biographie setzte Beitz' Tod kurz vor seinem 100. Geburtstag den Schlussstein dieser bundesrepublikanischen Deutungsgeschichte des Zitats. Die Bedeutung des Perikles-Satzes als Beitz' Lebensmotto bekräftigten die Angehörigen in ihrer Traueranzeige. ${ }^{88}$ Gewissermaßen von Staats wegen sanktionierte dann Bundespräsident Joachim Gauck die zur biographischen Deutung geronnene Selbstinterpretation von Beitz in seiner Traueransprache. In der Absicht, Beitz' Haltung in den Mittelpunkt zu rücken, beruft er sich, ausgehend von der Todesanzeige, in der er jenen ,altgriechischen Sinnspruch“ gefunden habe, auf den Satz des Perikles. „Besonder[e]“" Bedeutung schreibt er dem Zitat für die Würdigung von Beitz' Rettungsaktionen zu und legt dabei deutlich den Schwerpunkt auf den beispielhaften Mut des Managers (und dessen Ehefrau) ${ }^{89}$ Auch anlässlich der weiteren Lebensstationen des Verstorbenen hebt Gauck stark den Mut hervor, bringt aber auch Beitz' Eigenwilligkeit und Unkonventionalität zur Sprache, die es ihm ermöglicht habe, ,stets er selbst [zu] bleiben“: als Manifestation seiner ,,gefestigten Identität““. ${ }^{90}$ Tatsächlich sieht Gauck - „Das größte Denkmal [...] ist das Gedächtnis “91 - im Mut die Vorbildhaftigkeit von Beitz: „mehr Mut, mehr Verantwortungsbereitschaft, mehr Beitz“92. Das didaktische Ziel dieser Rede liegt nicht primär im Werben für Freiheit, die im Kern von Gaucks politischen Überzeugungen steht. ${ }^{93}$ Vielmehr geht sie von der Sorge des Bundespräsidenten um die Zukunft von Freiheit und Glück aus. Dass beides ohne Mut und die Bereitschaft zum Risiko in Gesellschaft, Wirtschaft und Politik fundamental bedroht ist, ist die politische Botschaft, die Gaucks Trauerrede aussendet.

Alle diese von Beitz angestoßenen und auf ihn fixierten Deutungen des PeriklesSatzes reflektieren unterschiedliche Interessen. Beitz selbst, der stets auf die Kontrolle seines Images bedacht war und, wie erwähnt, biographische Projekte über sich eng begleitete, dürfte es gegen Ende seines Lebens um den Versuch gegangen sein, eine autoritative Interpretation seiner Biographie vorzugeben, vor allem ihrer in den Augen der Nachwelt wichtigsten Phase. Als charakteristische Züge strich er dabei seine innere Unabhängigkeit im Handeln sowie seine unerschrockene Entscheidungskraft als Grundlage von Erfolg heraus. Von Seiten der Süddeutschen Zeitung aus lässt sich das Interview auch als ein geschichts- und gesellschaftspolitisches Instrument verstehen, um Beitz als ein Exempel für Zivilcourage zu präsentieren. Der Interviewer, Joachim Käppner, hat anschließend diesen Ansatz, in der Substanz ganz Beitz' Selbstverständnis

88 URL: https://trauer.sueddeutsche.de/mobil/traueranzeige/berthold-beitz (zuletzt aufgerufen am $01.02 .2020)$

${ }^{89}$ GAUCK 2013, 2.

${ }^{90}$ GAUCK 2013, 2 f. (Zitate: 3).

${ }^{91}$ GAUCK 2013, 4, erneut Perikles zitierend, was bedeutet, dass Gauck (oder der Konzipient der Rede im Bundespräsidialamt), nachdem er durch die Traueranzeige auf das ihm offensichtlich vorher nicht bekannte Zitat aufmerksam geworden war (,war gleich davon eingenommen“, 2), wahrscheinlich die Stelle nachgeschlagen hat. Bei dem zweiten Zitat des Bundespräsidenten handelt es sich wohl um eine Paraphrase von Thuk. 2,43,3, unmittelbar vor dem hier so bezeichneten Perikles-Satz.

${ }_{92}$ GAUCK 2013, 3.

${ }^{93}$ S., neben vielem, GAUCK 2012 (Freiheit. Ein Plädoyer) sowie FRANK 2012. 
folgend, als Biograph auf die gesamte Vita des Managers übertragen. Auch Bundespräsident Gauck nutzte das Zitat für eine geschichtspolitische Intention, wobei er weniger auf Beitz' vorbildhafte innere Freiheit als auf die von fehlender Risikobereitschaft ausgehende Gefahr abhob.

Diese spezielle Rezeptionsgeschichte des Perikles-Satzes schreibt Zahavi in Das Geheimnis der Freiheit mit eigener Akzentuierung und Darstellungsabsicht fort. Abrupt bricht er mit dem sich mittlerweile im kulturellen Gedächtnis etablierenden, von Beitz selbst entworfenen Bild. In seiner Konstruktion von Persönlichkeit und Wirken des Managers zeigt der Perikles-Satz nicht Mut in der Auseinandersetzung mit einer feindlichen Umwelt, sondern Verzagtheit im Umgang mit einem psychologischen Trauma, nicht Handeln als Ausdruck innerer Freiheit, sondern innere Unfreiheit durch fehlende Problemlösefähigkeit, nicht durch Entschlossenheit erworbenes Glück, sondern von Angst und Ignoranz erzeugtes Unglück. Ob Beitz tatsächlich ein unglückliches Leben geführt hatte, konnte allerdings niemand außer ihm selbst wissen. ${ }^{94}$

Maßgeblich für die Neudeutung des Zitats ist das offensichtliche geschichtsdidaktische Darstellungsinteresse des Regisseurs. Im wiedervereinigten Deutschland hat sich das fortgesetzte Erinnern an den Nationalsozialismus als ein unangefochtenes Paradigma etabliert. ${ }^{95}$ Schweigen und Vergessen, die lange Zeit in Teilen des Bürgertums Akzeptanz besessen hatten, tragen nun das „Stigma des Pathologischen“ ${ }^{96}$ Es herrscht Konsens, dass der Aufstieg und das internationale Ansehen der Bundesrepublik eng mit der Bereitschaft zur kontinuierlichen Auseinandersetzung mit dem Nationalsozialismus zusammenhingen und dass das Bekenntnis zur Täterschaft ein integraler Bestandteil der deutschen Identität und des politischen Selbstverständnisses der Bundesrepublik bleiben werde. ${ }^{97}$ „Historische Einbettung und befreiende Abkehr zugleich“ sind die miteinander korrespondierenden Ziele der Erinnerungskultur. ${ }^{98}$

\footnotetext{
${ }^{94}$ Beitz hat tatsächlich lange über seine Rettungsaktionen geschwiegen. Die Gründe dafür dürften in seiner Person wie in den gesellschaftlichen Rahmenbedingungen gelegen haben. Er selbst erklärte, die Phase des Aufbaus nach dem Krieg habe keinen Raum für die Reflexion des Geschehenen gelassen (BEITZ 2008A). Nach Einschätzung von KÄPPNER habe er kein „Gefangene[r] der Vergangenheit“ werden und seine Autorität aus wirtschaftlichem Erfolg heraus gewinnen wollen; möglicherweise hatte er auch Sorge vor Unverständnis und Ressentiments $(2010,140 ; 163)$. Tatsächlich war der Widerstand in der frühen Bundesrepublik umstritten und Teil von Deutungskämpfen (FREI 2005, 133 f.; 142-4). Nach seiner Auszeichnung in Yad Vashem, die seine Rettungstaten einer breiten Öffentlichkeit bekannt machte, gab Beitz häufig über die Episode seines Lebens Auskunft, auch in Begegnungen mit Schülern. Er stand überdies als Gesprächspartner für das Erinnerungsbuch von Schmalhausen sowie die Dissertation von Sandkühler zur Verfügung. Später unterstützte Beitz biographische Projekte über sich, wobei er aber die Kontrolle über die Darstellung und Deutung seines Lebens behalten wollte (hierzu sehr entschieden PÖTZL 2011, 11-6; 24-8, dessen Biographie zunächst nicht erscheinen durfte; für andere Erfahrungen mit Beitz s. KÄPPNER 2013, 22 und GALL 2002B, 13 f.). Insofern lässt sich schlussfolgern, dass Beitz die Vergangenheit nicht unterdrücken wollte, schon gar nicht die Episode in Boryslaw, aber dass er die Vergangenheit und deren Darstellung zu kontrollieren trachtete (und dafür im Zweifel auch legitime rechtliche Mittel einsetzte).

${ }^{95}$ Hierzu und zum Folgenden s. die grundlegenden Spezialstudien von HeTtLING 2000, 357; 362; 378, VAN LAAK 2002, 190 und HAMMERSTEIN 2017, bes. 400-5 sowie ferner HERBERT 2014, 1251 f.; SABROW 2017, bes. 329; WOLFRUM 2020, $179 \mathrm{f}$.

${ }^{96}$ So eindrücklich VAN LAAK 2000, 22.

${ }^{97}$ Dies ist das Résumé von Herberts Deutsche Geschichte im 20. Jahrhundert (2014, 1252). Mit Blick auf die Zukunft der Erinnerung stellt WOLFRUM 2020, 286 plastisch fest, die Vergangenheitsbewältigung in Deutschland sei ein ,ständiger Prozess und ein Lebenselixier für die Demokratie, die so ihren Triumph über die Diktatur tagtäglich erneuern kann und muss“. Zum internationalen Vorbildcharakter der deutschen Aufarbeitung der Vergangenheit s. HAMMERSTEIN 2017, 502.

${ }^{98}$ SABROW 2017, 329. Zu diesem Befund gehört aber auch ausdrücklich, dass in der Gesellschaft selbstverständlich nicht nur eine einzige Haltung zum Nationalsozialismus besteht, wie sie in dieser Bestandsaufnahme formuliert wird; s. hierzu GRYGLEWSKI 2020, 36.
} 
Inzwischen erhebt sich allerdings immer eindrücklicher das Problem, welche Konsequenzen die bereits im Jahr 1989 von Peter Graf Kielmansegg formulierte Einsicht hat, dass sich jeder Generation die Frage nach dem Umgang mit dem Nationalsozialismus aufs Neue stelle. ${ }^{99}$ Bedingt durch den generationellen Wandel und eine wachsende Heterogenität der Gesellschaft, verliert die Erinnerung an das „Dritte Reich“ und den Holocaust an Bindungskraft. ${ }^{100}$ Die wesentliche Verbindung der Menschen zum Nationalsozialismus besteht heutzutage darin, dass sie Deutsche sind oder in Deutschland leben. ${ }^{101}$ Eine vielfach geäußerte Befürchtung lautet, dass die abnehmende Relevanz des „Dritten Reiches“ und seiner Vergangenheit unter Deutschen und Zuwanderern den Boden für Revisionismus oder eine neue Schlussstrichmentalität bereiten könnte. ${ }^{102}$ Schon seit längerem wird daher die Forderung nach Veränderungen im Gedenken an den Nationalsozialismus und der Vermittlung seiner Geschichte erhoben, soll die Erinnerung auch künftig ihre identitätsbildende Wirkung für das Individuum und ihre innenwie außenpolitische Stabilisierungs- und Legitimierungsfunktion behalten. ${ }^{103}$

Das Geheimnis der Freiheit zeigt, personifiziert durch Berthold Beitz und Golo Mann, zwei auch in der Zukunft mögliche Formen des Umgangs mit dem Nationalsozialismus und deren jeweiligen Folgen. An dem fortwährenden Trauma, das Beitz zusetzt, demonstriert der Film die Ausweglosigkeit von Verschweigen und Verdrängen. Für ihn steht fest, dass die Erinnerung eine Form von Wirklichkeit bildet, die im Interesse der mentalen Gesundheit nicht geleugnet werden darf und nicht durch ein nach außen gerichtetes Handeln neutralisiert oder ersetzt werden kann. Zwar bietet die Filmhandlung keine unmittelbare Analogie zur Gegenwart, die sich gerade durch das Fehlen biographischer Bezüge zum Nationalsozialismus auszeichnet. Am Beispiel der Arbeit an dem Biographie-Projekt zu Krupp führt der Film jedoch vor, dass die Thematisierung der Vergangenheit nicht ausschließlich von persönlicher Betroffenheit ausgelöst wird, sondern von externen Impulsen ausgehen kann, die eine Konfrontation mit der Geschichte erzwingen. Geht man von der Unvergänglichkeit des „Dritten Reiches“ aus, das im kollektiven Gedächtnis der Deutschen, aber auch der globalen Welt tief verankert ist und dem entfliehen zu wollen eine Illusion bleibt, so stellt sich die Frage nach Mut, Freiheit und Glück, verglichen mit der Konstellation der Filmhandlung, lediglich in veränderter Gestalt.

Fatal wäre dem Film zufolge die Adaption eines verengten Freiheitsverständnisses, das sich schon bei Beitz als Selbsttäuschung erweist und den Einfluss der Vergangenheit auf das (Geschichts-)Bewusstsein leugnet. Nicht in der Verdrängung des Nationalsozialismus wird die Freiheit liegen, sondern in der aktiven Auseinandersetzung mit der Geschichte, deren Modus die analytische Durchdringung durch Aufarbeitung ist. Ohne sie werden, so vermittelt es der Film, die Geister der Erinnerung nicht

\footnotetext{
${ }^{99}$ GRAF KiELMANSEGG 1989, $95 \mathrm{f}$.

100 WIRSCHING 2012, 384. Hierzu gehört auch die Erforschung der Geschichte von staatlichen Institutionen sowie Unternehmen im Nationalsozialismus; über aktuelle Entwicklungen informiert WIRSCHING 2014, 17 f. Für das prominente Beispiel einer qualitativen Untersuchung zum generationell bedingten Wandel s. die Studie von ZÜLSDORF-KESTING 2007 zur Haltung von Jugendlichen zum Holocaust.

${ }^{101}$ WOLFRUM 2006, 501 sowie auch 399.

102 Einen Einblick in aktuelle Tendenzen bietet GRYGLEWSKI 2020, 36 f. mit zahlreichen Verweisen auf die derzeitige Publizistik.

${ }^{103}$ Den Horizont neuer Perspektiven reißt ASSMANN 2007, 235-71 auf. Zum aktuellen Stand der Debatte über gesellschaftsdidaktische Neujustierungen s. jetzt KNIGGE 2016 und MESSERSCHMIDT 2016 (mit besonderer Berücksichtigung der Auswirkungen der Migration), jeweils m. w. Lit. Grundsätzlich zum didaktischen Problem mit besonderer Berücksichtigung des Holocausts und dem aktuellen Forschungsstand s. BRÜNING 2018, 50-139. Zur Wirkung der Aufarbeitung der Geschichte des Nationalsozialismus im Ausland s. zuletzt umfassend NEIMAN 2019.
} 
gebannt bleiben. Infrage stünde dann nicht nur die Freiheit des Einzelnen mit seinem persönlichen Geschichtsbewusstsein. Gefährdet wäre auch das Glück der Gesellschaft als Ganze, die trotz zeitlichen Abstands und materiellen Wohlstands von einer unbeherrschten Vergangenheit umgetrieben würde, weil sie die Chance zur Aussöhnung mit der Vergangenheit verpasste. Da die Schrecken des Krieges abstrakt geworden sind, erfordert ein solcher Umgang mit der Vergangenheit nicht den Mut, sich eigenen Erinnerungen zu stellen, wie es der Film an Beitz' Beispiel darstellt. Notwendig wird vielmehr ein Ausbruch aus Lethargie oder Interesselosigkeit sein. Die Auseinandersetzung mit dem Nationalsozialismus erschöpft sich dann nicht mehr in einem persönlichen Bedürfnis, das aus biographischen Erfahrungen resultiert. Der Film enthält daher keine unmittelbar zu übernehmende historische Lektion im Genre des Biopics, das die Reproduzierbarkeit individuellen Verhaltens zeigt. Was er leistet, ist eine Vermittlung der Einsicht in die Unvergänglichkeit und Unverdrängbarkeit von Erinnerung und Geschichte sowie die Wirkungskraft des individuellen und kollektiven Gedächtnisses.

Das Geheimnis der Freiheit bekräftigt auch die hegemoniale Stellung professioneller Historiker ${ }^{104}$ im Erinnerungsdiskurs. Am Beispiel der Auslegung des PeriklesSatzes zeigt der Film die Defizite im Umgang mit der Vergangenheit und der Erinnerung auf, die aus Missverständnissen und Unwissenheit hervorgehen können. Die Vergangenheit angemessen zu interpretieren, erscheint als eine hermeneutische Herausforderung, vor der bloßer common sense kapituliert. Allein der Historiker vermag durch seine wissenschaftliche Kompetenz historische Einsichten zu kontextualisieren, sachlich korrekt zu deuten und für das Handeln in der Gegenwart nutzbar zu machen. In der Schlussszene zeigt sich, dass Beitz' Beharren auf dem Verdrängen und die Zurückweisung der Ratschläge Manns erfolglos geblieben sind. Aus dem Film lässt sich die Botschaft ableiten, dass auch in der Zukunft, wenn die Erinnerung an den Nationalsozialismus an Unmittelbarkeit verliert, das Erkennen historischer Zusammenhänge weiterhin eine Domäne der Historiker sein wird, deren Expertise im Interesse der Zukunftssicherung Vertrauen gebührt. Der Film plädiert dabei nicht für eine spezifische Form der Auseinandersetzung mit der Vergangenheit, die in der Bundesrepublik stets Gegenstand gesellschaftlicher Aushandlungsprozesse gewesen ist. Ihm kommt es allein auf die mit der zeitlichen Distanz möglicherweise immer weniger drängend wirkende Notwendigkeit von Erinnerung überhaupt an.

\section{Thukydides und die Erinnerung an den Nationalsozialismus}

Offen ist zuletzt noch die Frage, ob sich in Das Geheimnis der Freiheit auch noch nach etwa 2400 Jahren der Thukydides' Peloponnesischem Krieg zugrundeliegende Ewigkeitsanspruch erweist, der auf der Erkenntnis anthropologischer Konstanten und politischer Muster beruht.

Aus dem Abgleich der Filmhandlung mit dem Dictum des Perikles ergeben sich fundamentale Unterschiede zwischen Vorlage und Interpretation. Bereits der Wortlaut des Zitats lässt sich nicht mit dessen Funktion für den Plot und dem vom Regisseur angestrebten Narrativ vereinbaren. Erst seine Transformation durch die Fortlassung störender Satzteile und die Umwandlung eines Imperativs in einen Indikativ Präsens macht die Instrumentalisierung des Satzes in dem gewünschten Sinne möglich. Angesichts der Akribie, die zu den Kennzeichen des Films gehört, ist anzunehmen, dass es sich hierbei um eine bewusste Manipulation des Textes handelt. Dass die Veränderung des Zitats

${ }^{104}$ S. hierzu VAN LAAK 2000, 22. 
kein philologischer Irrtum, ${ }^{105}$ sondern ein Kunstgriff ist, scheint Zahavi dadurch zu signalisieren, dass Golo Mann das Zitat im Gespräch mit Berthold Beitz zwar präzise und wie einstudiert wiedergibt, seine Übersetzung jedoch mit einer relativierenden Bemerkung einleitet (,heißt es ungefähr"), die sich offensichtlich mehr an den Zuschauer als an Beitz richtet.

Den von Thukydides beanspruchten überzeitlichen Gehalt des thukydideischen Geschichtswerks, der nach dem Anspruch des Historikers in der Konstruktion des Epitaphios und in dem Satz des Perikles steckt, gibt Zahavi mit seiner Bearbeitung preis. Der Regisseur möchte aus dem Geschichtswerk keine Einsichten für das Verständnis der Gegenwart und adäquates Handeln ableiten. Vielmehr verfolgt er die Absicht, eigene Überzeugungen mithilfe des Textes des Thukydides zu belegen und zu verbreiten, wobei sein Ansatz auf eine von ihm selbst erkannte Veränderung am Original zurückgeht, die von der historischen Gestalt Berthold Beitz selbst stammt. Gemäß den hermeneutischen Prämissen des Thukydides, dessen Autorität Zahavi reklamiert, ist aber die vom Film aus dem Text herauspräparierte Gesetzmäßigkeit, dass der Mut, der Vergangenheit entgegenzublicken, zu Freiheit und Glück führen werde, ungültig und insofern wertlos. Mehr noch: Die vom Film präsentierten Voraussetzungen für ein gelingendes Leben und gesellschaftliche Prosperität, stellt Perikles selbst, dem es um die Mobilisierung der Bürgerschaft für den Krieg geht, nicht einmal auf.

Funktioniert der Perikles-Satz in Das Geheimnis der Freiheit schon nur bei Eingriffen in den Wortlaut, so bedarf es auch einer neuen inhaltlichen und begrifflichen Aufladung, um die intendierte Sinnstiftung erfüllen zu können. Sie tritt, wie dargelegt, in unterschiedlichen Perspektiven auf Vergangenheit und Zukunft, in einem unterschiedlichen Verständnis von Freiheit und Mut sowie in ganz unterschiedlichen Konkretisierungen dieser Werte zutage. Die Ursache für diese Diskrepanzen liegt in den unmittelbaren Problemen von Bundesrepublik und perikleischem Athen, die jeweils mit dem Satz des Perikles adressiert werden. Während Zahavi auf den Umgang mit der nationalsozialistischen Vergangenheit zielt, richtet sich Perikles auf die militärische Behauptung Athens im Peloponnesischen Krieg. Über die Veränderung am Text hinaus operiert der Film also mit einer kompletten Dekontextualisierung des Epitaphios.

Immerhin bestehen auch Gemeinsamkeiten zwischen Original und Adaption des Zitats. Sowohl Zahavi und seine Filmfigur als auch der Perikles des Thukydides ringen angesichts je spezifischer Herausforderungen um die Gestaltung der Zukunft. Auch wenn es zwischen dem Hauptsatz in der Übersetzung Golo Manns und dem Original wegen des grammatischen Eingriffs keine Verbindung gibt, bleiben unabhängig von inhaltlichen Vorstellungen die Zusammenhänge in der Partizipialkonstruktion gewahrt: das doppelte Abhängigkeitsverhältnis von Glück, Freiheit und Mut. Indes handelt es sich dabei um einen wahrscheinlich weitgehend konsensfähigen Topos, der, ideologisch ungebunden, nahe der Grenze zur Trivialität liegt.

Letztlich besteht das Überzeitliche dieses amputierten $\kappa \tau \tilde{\eta} \mu \alpha$ hauptsächlich in seiner Adaptionsfähigkeit für beliebige inhaltliche Vorstellungen und politische Ziele. Gerade die sentenzhafte Allgemeingültigkeit dürfte ihm über die Zeitläufte hinweg Beständigkeit gesichert haben. So bietet er Anregungen, über die in ihm erwähnten Zusammenhänge die eigene Welt und die Entscheidungszusammenhänge zu reflektieren und Handlungsoptionen zu erwägen. Zumindest was dieses Zitat betrifft, liegen Aktualität und Anschlussfähigkeit des Thukydides nicht auf der inhaltlichen Ebene, sondern in der sprachlichen Form. Jenseits seiner Wirkmächtigkeit als Impulsgeber vermag der

${ }^{105}$ Prinzipiell wäre dies vorstellbar, weil sich in der deutschen Übersetzung der Imperativ nicht ohne Weiteres in die syntaktische Struktur einfügt, sei es, dass die Partizipien wörtlich oder als Nebensatz wiedergegeben werden. 
Satz des Perikles auch als Legitimationsquelle dienen. Einerseits liefert gerade die lange Rezeptionsgeschichte des Thukydides einen Beleg für die Triftigkeit seines Werkes und der ihm zu entnehmenden Einsichten. Andererseits verleiht er einem Gegenstand die noch immer zugkräftige Aura der Antike, deren vermeintliche Weisheit wie eine Art intellektuelles Qualitätssiegel wirkt. Bemerkenswert ist indes, dass der Film hinsichtlich der Zukunft der Erinnerung so stark auf Historizität insistiert, diese aber zugleich durch seine Instrumentalisierung des Thukydides verrät. Insofern konterkariert er die eigene, am Schicksal von Beitz namhaft gemachte Botschaft.

Für den geschichtspolitischen Diskurs der Bundesrepublik im 21. Jahrhundert hat die Anrufung des Thukydides jedoch auch in der Substanz keinen Neuigkeitswert. Was Zahavi mit Hilfe des Perikles-Satzes vermitteln möchte, ist ein Kerngedanke der deutschen Erinnerungskultur, der bereits von Mitte der 1970er Jahre in vor und für die Nation gehaltenen Reden der Bundespräsidenten Walter Scheel und Richard v. Weizsäcker sowie der Bundeskanzler Helmut Schmidt und Helmut Kohl formuliert und weiterentwickelt worden ist. In teilweise beinahe identischem Wortlaut und in eindringlichen Formulierungen, die zumindest in Weizsäckers Fall weltweite Aufmerksamkeit erlangt haben, wandten sie sich gegen eine Schlussstrichmentalität und warben für die Erkenntnis, dass die Freiheit von der Vergangenheit nur durch die Annahme der Vergangenheit erreicht werden könne.

Möglicherweise bieten diese Reden und ihre Entstehungsgeschichte nicht das gleiche Potential für eine Dramatisierung wie die Inszenierung eines fiktiven erinnerungspolitischen Duells im Anschluss an die Selbst- und Fremddeutung der Jahrhundertgestalt Beitz. Aber die vom Regisseur gewählte Form der Fiktionalisierung beraubt Das Geheimnis der Freiheit seiner Überzeugungskraft. Als entscheidendes Hemmnis erweist sich gerade Zahavis Praxis der Antikenrezeption. Für seine altertumsgestützten erinnerungspolitischen Forderungen bietet er nur einen Pseudo-Thukydides auf. Die Erkenntnis über den Zusammenhang von Erinnerung und Zukunft, die er dem Publikum präsentiert, ist letztlich seine persönliche Ansicht, drapiert mit der Autorität des Perikles.

\section{Schluss}

Die Untersuchung der Rezeption des Perikles-Satzes in Das Geheimnis der Freiheit, der im Plot als Angelpunkt der Kontroverse um den Umgang mit dem Nationalsozialismus dient, hat erwiesen, dass sich das Zitat nur durch Manipulation für die geschichtspolitischen Absichten des Regisseurs Zahavi anwenden lässt. Thukydides und die mit seinem Namen sowie mit der Antike verbundenen Assoziationen sind ein bloßes Etikett. Es stillt weder das eine Auseinandersetzung mit der Geschichte auslösende Orientierungsbedürfnis noch regt es durch Alterität zur Reflexion über die Gegenwart an. Perspektiven für den Umgang mit dem Nationalsozialismus in der Bundesrepublik des 21. Jahrhunderts können sich nicht auf die argumentative Kraft des thukydideischen $\kappa \tau \tilde{\eta} \mu \alpha$ in Zahavis Deutung stützen. Vielmehr werden die Intentionen des Films durch ein doppelt gebrochenes Historizitätsversprechen zur Makulatur: durch die Abänderung des Zitats entgegen den erkenntnistheoretischen Grundlagen des dennoch als unanfechtbare Autorität in Anspruch genommenen Thukydides und durch die Berufung auf die Überlegenheit der geschichtswissenschaftlichen Methodik gegenüber laienhaften Zugriffen auf die Geschichte.

Mit dieser Form der Antikenrezeption verbinden sich zwei Probleme. Zum einen geht der Regisseur offenbar von der Prämisse aus, dass die Geschichte nur bei einer 
Identität zwischen Gegenwart und Vergangenheit Relevanz für die Zukunft entfalten kann. Hinter dieser Auffassung ist das überkommene Konzept einer historia magistra vitae, einer Vorstellung von der Geschichte als Arsenal von Handlungsanweisungen, erkennbar. Sich von einem solchen Verständnis von Geschichte und Geschichtsschreibung prinzipiell abzusetzen, hatte schon den Innovationsgehalt von Thukydides' Peloponnesischem Krieg bestimmt. Umso mehr gilt dies für die sich spätestens seit der Sattelzeit auftuenden Alteritäten zwischen der Moderne und allen vorhergehenden Epochen. ${ }^{106}$ Eine zumindest punktuelle Ineinssetzung der Antike mit der Gegenwart unterschätzt die für die jeweiligen Zeiten konstitutiven Charakteristika und Dynamiken und behindert dadurch gerade das Verständnis der Eigengesetzlichkeiten der Vergleichszeit, die in Das Geheimnis der Freiheit die deutsche Geschichte im 20. und 21. Jahrhundert ist. Statt für eine plakative Form des Lernens aus der Geschichte hätte Zahavi das ja unzweifelhaft mit Beitz' Biographie verbundene Thukydides-Zitat für eine Reflexion über Glück, Freiheit und Mut einsetzen können, die, von einer Auseinandersetzung über den Wortlaut ausgehend, zu einer eigenständigen Beurteilung der Verhältnisse der Gegenwart und der Herausforderungen der Zukunft auffordert. Ein solches Vorgehen hätte dann auch der Historik von Zahavis Vorbild Thukydides entsprochen. Zum anderen verführt die Antikenrezeption, die Das Geheimnis der Freiheit praktiziert, zur Banalisierung der Vergangenheit. Durch eine sinnstiftende, Alteritäten ausblendende direkte Übernahme reduziert sich der Erkenntnisgehalt von Einsichten aus der Geschichte wie beispielsweise des Perikles-Satzes auf ebenso konsensfähige wie triviale Erkenntnisse, die einer historischen Fundierung eigentlich nicht bedürfen. Auf eine solche Weise verliert die Beschäftigung mit der Geschichte das ihr eigene Potential, das auf der Erforschung der Vergangenheit und deren Narrativierung im Sinne einer Zukunftsgestaltung beruht. Aus Geschichte wird Popularphilosophie.

Versuche wie derjenige Zahavis, ein geschichtspolitisches Problem der Gegenwart mithilfe einer antiken Tradition zu lösen, können jedoch nicht nur zu hermeneutischen Blockaden führen, sondern auch den Rekurs auf bereits vorhandene zeitgeschichtliche Deutungsangebote erschweren. Die Thukydides unterstellten Einblicke in die Bedingungen des Glücks sind integrale Bestandteile der erwähnten politischen Positionsbestimmungen der 1970 und 1980er Jahre zum Problem der Erinnerung, die selbst zu Ausgangspunkten für den Diskurs um die Zukunft der Geschichte werden könnten. Sie bedürften dafür lediglich der (Re-)Aktivierung. Auf ihrer Grundlage ließen sich präziser und wirkungsvoller die Herausforderungen erörtern, inwieweit die kathartische Wirkung, die ihrem Plädoyer für die Aufarbeitung der Geschichte zugeschrieben wurde, ${ }^{107}$ auch künftig noch relevant ist und wie sie bei fortschreitender Historisierung des Nationalsozialismus erzielt werden könne. An dieser Stelle muss Das Geheimnis der Freiheit mit seinem im generationellen Wandel immer anachronistischer werdenden biographischen Beispiel Beitz scheitern, dessen Existenzberechtigung mit Blick auf die Zukunft hauptsächlich darin liegen dürfte, dass es als Träger des Perikles-Satzes fungiert. Die Absicht, mit Thukydides zu operieren, führt daher zu einer Verkennung der tatsächlichen Problemlage, für deren Lösung er in Anspruch genommen wird.

So hängt, alles in allem, die Antwort auf die Frage nach der gesellschaftsdidaktischen Aktualität des Thukydides für die deutsche Erinnerungskultur, zugespitzt auf die Formel „Thukydides als Therapeut?“, allein von dem reflektierten Verständnis des historischen Lernens und der daraus abzuleitenden Form der Antikenrezeption dessen

\footnotetext{
${ }^{106}$ KOSELLECK 1976/1989.

${ }^{107} \mathrm{Zu}$ dergleichen zeitgenössischen Reaktionen s. HAMMERSTEIN 2017, 246.
} 
ab, der sich Impulse aus der Lektüre des Peloponnesischen Kriegs erhofft und dadurch in Thukydides einen wirklichen „Besitz“ für die Bundesrepublik entdeckt.

\section{Literatur}

\section{$\underline{1 . \text { Quellen }}$}

\section{a) Edition des Thukydides}

Thucydidis Historiae, rec. H. S. Stuart, tomus prior, Oxonii 1942.

\section{b) Konsultierte Übersetzungen des Thukydides}

HobBES 1848: Th. Hobbes, The English Works. Vol. VIII: The History of the Grecian War Written by Thucydides, Vol. 1, London 1848.

LANDMAnN 2002: Thukydides, Der Peloponnesische Krieg, hg. u. übers. v. G. P. Landmann, Düsseldorf/Zürich 2002.

DE Romilly 2009: Thucydide, La guerre du Péloponnèse. Tome II, $1^{\text {re }}$ partie, livre II. Texte établi et traduit par J. de Romilly, Paris $2009^{7}$.

VALlA 1492/2008: M. Chambers (ed.), Valla's Translation of Thucydides in Vat. Lat. 1801. With the Reproduction of the Codex (= Studi e testi 208), Città del Vaticano 2008.

Weißenberger 2017: Thukydides, Der Peloponnesische Krieg. Griechisch-deutsch. Übers. v. M. Weißenberger. Mit einer Einleitung von A. Rengakos, Berlin/Boston 2017.

c) Golo Manns Krupp-Biographie

Krupp. Originalmanuskript, Schweizerisches Literaturarchiv Bern, Sig. SLA-GM-A-1$\mathrm{g} / 3-4$.

Krupp. 2. Fassung, Schweizerisches Literaturarchiv Bern, Sig. SLA-GM-A-1-g/5-11 [mit der Einarbeitung der handschriftlichen Korrekturen des Originalmanuskripts].

\section{d) Zitierte Quellen zu Beitz' Rettungsaktionen}

BeITZ 2008(A): Berthold Beitz über Freiheit, Süddeutsche Zeitung Nr. 28 v. 02.02.2008, ROM8.

BeITZ 2008(B): „Ich mußte es einfach tun“. Interview mit Berthold Beitz, sueddeutsche.de am 01.02.2008, SZ Archiv LibraryNet, Dokument-ID: A45329900.

BRIEFE AN BEITZ 2008: „Es ist eine Lebenskunst, das Unglück zu verstehen“: Briefe an Berthold Beitz, sueddeutsche.de am 01.02.2008, SZ Archiv LibrayNet, Dokument-ID: A45329897. 


\section{$\underline{\text { 2. Forschungsliteratur }}$}

ABELSHAUSER 2002: W. Abelshauser, Rüstungsschmiede der Nation? Der Kruppkonzern im Dritten Reich und in der Nachkriegszeit. 1933 bis 1951, in: Gall 2002a, 267472.

AdORno 1959: Th. W. Adorno, Was bedeutet: Aufarbeitung der Vergangenheit, in: Gesammelte Schriften, hg. v. R. Tiedemann, Bd. 10.2: Kulturkritik und Gesellschaft II. Eingriffe, Stichwort, Anhang, Frankfurt a. M. 2016 6 , 555-572. [als Vortrag erstmals 1959 gehalten]

AsSmann 2007: A. Assmann, Der lange Schatten der Vergangenheit. Erinnerungskultur und Geschichtspolitik, Bonn 2007.

BALOT 2004: R. Balot, Courage in the Democratic Polis, CQ 54, 2004, 406-423.

Balot 2009: R. K. Balot, Freedom to Rule. Athenian Imperialism and Democratic Masculinity, in: D. Tabachnick/T. Koivukoski (eds.), Enduring Empire. Ancient Lessons for Global Politics, Toronto 2009, 54-68.

BECKER 2013: M. Becker, Geschichtspolitik in der „Berliner Republik“. Konzeptionen und Kontroversen, Wiesbaden 2013.

Benz 2014: W. Benz, Der deutsche Widerstand gegen Hitler, München 2014.

BERLIN 1969: I. Berlin, Four Essays on Liberty, Oxford 1969.

BitTerli 2005: U. Bitterli, Golo Mann. Instanz und Außenseiter. Eine Biographie, Reinbek 2005.

BLEICKen 1995: J. Bleicken, Die athenische Demokratie, Paderborn u. a. $1995^{4}$.

BosworTH 2000: A. B. Bosworth, The Historical Context of Thucydides' Funeral Oration, JHS 120, 2000, 1-16.

BRINGMANN 2019: K. Bringmann, Das Volk regiert sich selbst. Eine Geschichte der Demokratie, Darmstadt 2019.

BRÜNING 2018: Chr. I. Brüning, Holocaust Education in der heterogenen Gesellschaft. Eine Studie zum Einsatz videographierter Zeugnisse von Überlebenden der nationalsozialistischen Genozide im Unterricht, Schwalbach am Taunus 2018.

Classen/Steup 1914: J. Classen/J. Steup, Thukydides, Zweiter Band. Zweites Buch. Berlin 1914 , ND 1982.

CONZE 2009: E. Conze, Die Suche nach Sicherheit. Eine Geschichte der Bundesrepublik Deutschland von 1949 bis in die Gegenwart, München 2009.

DUDEK 1992: P. Dudek, „Vergangenheitsbewältigung“. Zur Problematik eines umstrittenen Begriffs, in: Aus Politik und Zeitgeschichte B 1-2, 1992, 44-53.

Flashar 1969: H. Flashar, Der Epitaphios des Perikles. Seine Funktion im Geschichtswerk des Thukydides, Heidelberg 1969.

FLASHAR 1975: H. Flashar, Nachträgliche Bemerkungen, in: Gaiser 1975, 102-108.

FORSDYKE 2017: S. Forsdyke, Thucydides' Historical Method, in: R. K. Balot/S. Forsdyke/E. Foster (eds.), The Oxford Handbook of Thucydides, Oxford 2017, 19-38.

FRANK 2012: M. Frank, Gauck. Eine Biographie, Berlin 2012. 
FREI 1996: N. Frei, Vergangenheitspolitik. Die Anfänge der Bundesrepublik und die NS-Vergangenheit, München 1996.

FREI 2005: N. Frei, 1945 und wir. Das Dritte Reich im Bewußtsein der Deutschen, München 2005.

FREIMÜLLER 2007: T. Freimüller, Alexander Mitscherlich. Gesellschaftsdiagnosen und Psychoanalyse nach Hitler (= Beiträge zur Geschichte des 20. Jahrhunderts 6), Göttingen 2007.

FRIZ 1988: D. M. Friz, Alfried Krupp und Berthold Beitz. Der Erbe und sein Statthalter, Zürich/Wiesbaden 1988.

JAMES 2011: H. James, Krupp. Deutsche Legende und globales Unternehmen, München 2011.

GADAMER 1975: H.-G. Gadamer, Wahrheit und Methode. Grundzüge einer philosophischen Hermeneutik, Tübingen $1975^{3}$.

GAISER 1975: K. Gaiser, Das Staatsmodell des Thukydides. Zur Rede des Perikles für die Gefallenen (= Heidelberger Texte. Didaktische Reihe 8), Heidelberg 1975.

Gall 2000A: L. Gall (Hg.), Krupp im 20. Jahrhundert. Die Geschichte des Unternehmens vom Ersten Weltkrieg bis zur Gründung der Stiftung, Berlin 2002.

GALL 2002B: L. Gall, Einleitung, in: Gall 2002a, 9-14.

GALl 2002C: L. Gall, Von der Entlassung Alfried Krupp von Bohlen und Halbachs bis zur Errichtung seiner Stiftung. 1951-1967/68, in: Gall 2002a, 473-589.

GAUCK 2012: J. Gauck, Freiheit. Ein Plädoyer, München 2012.

GAUCK 2013: Bundespräsident J. Gauck bei der Gedenkfeier für Berthold Beitz am 26. September 2013 in Essen, URL: https://www.bundespraesident.de/SharedDocs/Reden/DE/Joachim-Gauck/Reden/2013/09/130926-Bertold-Beitz.html [sic!] (zuletzt aufgerufen am 28.04.2020).

Gomme 1945: A. W. Gomme, A Historical Commentary on Thucydides, The Ten Years' War, Vol. II: Books II-III, Oxford 1945, ND 1996.

GRYGLEWSKi 2020: E. Gryglewski, Gedenken an den Holocaust. Ritual und Reflexion, Aus Politik und Zeitgeschichte 70/33-34, 2020, 34-39.

HAMMERSTEIN 2017: K. Hammerstein, Gemeinsame Vergangenheit - getrennte Erinnerung? Der Nationalsozialismus in Gedächtnisdiskursen und Identitätskonstruktionen von Bundesrepublik Deutschland, DDR und Österreich (= Diktaturen und ihre Überwindung im 20. und 21. Jahrhundert 11), Göttingen 2017.

HANSEN 1995: M. H. Hansen, Die athenische Demokratie im Zeitalter des Demosthenes. Struktur, Prinzipien und Selbstverständnis, Berlin 1995.

Herbert 2014: U. Herbert, Geschichte Deutschlands im 20. Jahrhundert, München 2014.

Hettling 2000: M. Hettling, Die Historisierung der Erinnerung - Westdeutsche Rezeptionen der nationalsozialistischen Vergangenheit, Tel Aviver Jahrbuch für deutsche Geschichte 19, 2000, 357-378. 
HoRnBlower 1997: S. Hornblower, A Commentary on Thucydides. Vol. I: Books IIII, Oxford $1997^{2}$.

KagAN 1990: D. Kagan, Pericles of Athens and the Birth of Democracy, London 1990.

KAKRIDIS 1981: J. Th. Kakridis, Der Thukydideische Epitaphios. Ein stilistischer Kommentar (= Zetemata 26), München 1981.

KÄPPNER 2010: J. Käppner, Berthold Beitz. Die Biographie, Berlin $2010^{4}$.

KÄPPNER 2013: J. Käppner, Berthold Beitz. Die Biographie. Mit einem Vorwort von Helmut Schmidt, Berlin 2013.

GRAF KIELMANSEGG 1989: P. Graf Kielmansegg, Lange Schatten. Vom Umgang der Deutschen mit der nationalsozialistischen Vergangenheit, Berlin 1989.

KNIGGE 2016: V. Knigge, „Das radikal Böse ist das, was nicht hätte passieren dürfen“. Unannehmbare Geschichte begreifen, Aus Politik und Zeitgeschichte 66/3-4, 2016, 39.

KöNIG 1998: W. König, Von der Diktatur zur Demokratie oder Was ist Vergangenheitsbewältigung, in: H. König/M. Kohlstruck/A. Wöll (Hgg.), Vergangenheitsbewältigung am Ende des zwanzigsten Jahrhunderts (= Leviathan Sonderheft 18), Opladen/Wiesbaden 1998, 371-392.

KoHL 1985: H. Kohl, Das Geheimnis der Erlösung heißt Erinnerung. Ansprache zum 40. Jahrestag der Befreiung der Gefangenen aus den Konzentrationslagern, gehalten am 21. April 1985 in Bergen-Belsen, in: Die unentrinnbare Gegenwart der Geschichte, Bonn 1988, 5-18.

KOSELLECK 1976/1989: R. Koselleck, „Erfahrungsraum“ und „Erwartungshorizont“ zwei historische Kategorien, in: U. Engelhardt/V. Sellin/H. Stuke (Hgg.), Soziale Bewegung und politische Verfassung. Beiträge zur Geschichte der modernen Welt, Stuttgart 1976, 13-33, ND in: R. Koselleck, Vergangene Zukunft. Zur Semantik geschichtlicher Zeiten, Frankfurt a. M. 1989, 349-375.

KÜHNER/BLASS 1892: R. Kühner/Fr. Blass, Ausführliche Grammatik der griechischen Sprache. Erster Teil: Elementar- und Formenlehre. Zweiter Band, Hannover $1892^{3}$, ND Darmstadt 2015.

KÜHNER/GERTH 1898: R. Kühner/B. Gerth, Ausführliche Grammatik der griechischen Sprache. Zweiter Teil: Satzlehre. Erster Band, Hannover 1898³ , ND Darmstadt 2015.

VAN LAAK 2000: D. van Laak, Widerstand gegen die Geschichtsgewalt. Zur Kritik an der „Vergangenheitsbewältigung“, in: N. Frei/D. van Laak/M. Stolleis (Hgg.), Geschichte vor Gericht. Historiker, Richter und die Suche nach Gerechtigkeit, München 200, 11-28.

VAN LAAK 2002: D. van Laak, Der Platz des Holocaust im deutschen Geschichtsbild, in: K. H. Jarausch/M. Sabrow (Hgg.), Die historische Meistererzählung. Deutungslinien der deutschen Nationalgeschichte seit 1945, Göttingen 2002, 163-193.

LAHME 2009: T. Lahme, Golo Mann. Biographie, Frankfurt a. M. 2009.

LANDMAnN 1974: G. P. Landmann, Das Lob Athens in der Grabrede des Perikles (Thukydides II 34-41), MH 31, 1974, 65-95. 
LehmanN 2008: G. A. Lehmann, Perikles. Staatsmann und Stratege im klassischen Athen. Eine Biographie, München 2008.

LORAUX 1993: N. Loraux, The Invention of Athens. The Funeral Oration in the Classical City, New York 1993, ND 2006 (erstmals 1981 in frz. Sprache).

LÜBBE 1983: H. Lübbe, Der Nationalsozialismus im deutschen Nachkriegsbewußtsein, HZ 236, 1983, 579-599.

MACLEOD 1996: C. MacLeod, Thucydides and Tragedy, in: Collected Essays, Oxford 1996, 140-159.

MEIER 1980: Chr. Meier, Die Entstehung des Politischen bei den Griechen, Frankfurt a. M. 1980.

MESSERSCHMIDT 2016: A. Messerschmidt, Geschichtsbewusstsein ohne Identitätsbesetzungen - kritische Gedenkstättenpädagogik in der Migrationsgesellschaft, Aus Politik und Zeitgeschichte 66/3-4, 2016, 16-22.

MuHLACK 2011: U. Muhlack, Herodotus und Thucydides in the View of NineteenthCentury German Historians, in: A. Lianeri (ed.), The Western Time of Ancient History: Historiographical Encounters with the Greek and Roman Pasts, Cambridge 2011, 179209.

NeIMAN 2019: S. Neiman, Learning from the Germans. Race and the Memory of Evil. New York 2019.

OBER 2010: J. Ober, Thuydides on Athen's Democratic Advantage in the Archidamian War, in: Pritchard 2010a, 65-87.

OBER 2015: J. Ober, Das antike Griechenland. Eine neue Geschichte, Stuttgart 2015.

PöTZl 2011: N. F. Pötzl, Beitz. Eine deutsche Geschichte, München 2011.

PRINZ 1997: Karl Prinz, Epitaphios Logos. Struktur, Funktion und Bedeutung der Bestattungsreden im Athen des 5. und 4. Jahrhunderts (= Europäische Hochschulschriften III. 747), Frankfurt a. M. u. a. 1997.

PRITCHARD 2010A: D. M. Pritchard (ed.), War, Democracy and Culture in Classical Athens, Cambridge 2010.

PRITCHARD 2010B: D. M. Pritchard, The Symbiosis between Democracy and War. The Case of Ancient Athens, in: Pritchard 2010a, 1-62.

RaAflaub 2004: K. A. Raaflaub, The Discovery of Freedom in Ancient Greece, Chicago/London 2004.

RaAflaub 2006: K. A. Raaflaub, Thucydides on Democracy and Oligarchy, in: A. Rengakos/A. Tsakmakis (eds.), Brill's Companion to Thucydides, Leiden/Boston 2006, 189-222.

RaAflaub 2013: K. A. Raaflaub, Ktēma es aiei: Thucydides' Concept of „Learning through History“" and its Realization in his Work, in: A. Tsakmakis/M. Tamiolaki (eds.), Thucydides between History and Literature (= Trends in Classics - Suppl. Volumes 17), Berlin/Boston 2013, 3-21.

RaAflaub 2016: K. A. Raaflaub, Die große Herausforderung. Herodot, Thukydides und die Erfindung einer neuen Form von Geschichtsschreibung, HZ 302, 2016, 593 622 . 
REICHEL 2007: P. Reichel, Vergangenheitsbewältigung in Deutschland. Die Auseinandersetzung mit der NS-Diktatur in Politik und Justiz, München $2007^{2}$.

RoISMAn 2005: J. Roisman, The Rhetoric of Manhood. Masculinity and the Attic Orators, Berkeley 2005.

RÜSEN 1983: J. Rüsen, Historische Vernunft. Grünzüge einer Historik I: Die Grundlagen der Geschichtswissenschaft, Göttingen 1983.

Rusten 1985: J. S. Rusten, Two Lives or Three? Pericles on the Athenian Character (Thucydides 2.40.1-2), CQ 35, 1985, 14-19.

RUSTEN 1986: J. S. Rusten, Structure, Style, and Sense in Interpreting Thucydides: The Soldier's Choice (Thuc. 2.42.4), HSCPh 90, 1986, 49-76.

Rusten 1989: J. S. Rusten (ed.), Thucydides, The Peloponnesian War. Book II, Cambridge 1989.

SABRow 2017: M. Sabrow, Zeit-Verhältnisse. Das Gedächtnis des 20. Jahrhunderts, in: M. Sabrow/P. U. Weiß (Hgg.), Das 20. Jahrhundert vermessen. Signaturen eines vergangenen Zeitalters, Göttingen 2017, 304-330.

SANDKÜHLER 1996: Th. Sandkühler, „Endlösung“ in Galizien. Der Judenmord in Ostpolen und die Rettungsinitiativen von Berthold Beitz 1941-1944, Bonn 1996.

SANDKÜHLER 2004: Th. Sandkühler, Berthold Beitz und die „Endlösung der Judenfrage“" im Distrikt Galizien, 1941-1944, in: G. Hirschfeld/T. Jersak (Hgg.), Karrieren im Nationalsozialismus. Funktionseliten zwischen Mitwirkung und Distanz, Frankfurt a. M./New York 2004, 99-125.

SCHEEL 1975: W. Scheel, Hitler war kein unentrinnbares Schicksal. Sind wir klüger geworden? Rede zum 30. Jahrestag der Beendigung des Zweiten Weltkriegs (8. Mai 1945) in der Schloßkirche der Universität Bonn, in: F. Franken (Hg.), Repräsentanten der Republik. Die deutschen Bundespräsidenten in Reden und Zeitbildern, Bonn 1989, 177-184.

Schmalhausen 1991: B. Schmalhausen, Berthold Beitz im Dritten Reich. Mensch in unmenschlicher Zeit, Essen 1991.

SCHMIDT 1975: H. Schmidt, Ansprache vor dem Kabinett zum 8. Mai 1975, URL: https://www.helmut-schmidt.de/aktuelles/nachrichten/detail/artikel/der-8-mai-1945brachte-uns-die-befreiung-von-der-nationalsozialistischen-gewaltherrschaft/ (zuletzt aufgerufen am 30.06.2020) [vom BK korrigiertes Typoskript]

Strasburger 1954: H. Strasburger, Der Einzelne und die Gemeinschaft im Denken der Griechen, HZ 117, 1954, 227-248.

Strasburger 1958: H. Strasburger, Thukydides und die Selbstdarstellung der Athener, Hermes 86, 1958, 17-40.

THAMER 2006: H.-U. Thamer, Die westdeutsche Erinnerung an die NS-Diktatur in der Nachkriegszeit, in: P. März/H.-J. Veen (Hgg.), Woran erinnern? Der Kommunismus in der deutschen Erinnerungskultur, Köln 2006, 51-70.

V. WEIZSÄCKER 1985: Bundespräsident R. v. Weizsäcker bei der Gedenkveranstaltung im Plenarsaal des Deutschen Bundestages zum 40. Jahrestag des Endes des Zweiten 
Weltkrieges in Europa am 8. Mai 1985, URL: https://www.bundespraesident.de/SharedDocs/Downloads/DE/Reden/2015/02/150202-RvW-Rede-8-Mai1985.pdf? blob=publicationFile (zuletzt aufgerufen am 10.02.2020)

WILl 2003: W. Will, Thukydides und Perikles. Der Historiker und sein Held (= Antiquitas I. 51), Bonn 2003.

WIRSCHING 2006: A. Wirsching, Abschied vom Provisorium 1982-1990 (= Geschichte der Bundesrepublik Deutschland 6), München 2006.

WiRSCHING 2012: A. Wirsching, Der Preis der Freiheit. Geschichte Europas in unserer Zeit, Bonn 2012.

WIRSCHING 2014: A. Wirsching, Zur aktuellen Situation der „Aufarbeitung der NSZeit“, Südosteuropa Mitteilungen 4, 2014, 14-27.

WOLFRUM 1999: E. Wolfrum, Geschichtspolitik in der Bundesrepublik Deutschland. Der Weg zur bundesrepublikanischen Erinnerung 1948-1990, Darmstadt 1999.

WOLFRUM 2001: E. Wolfrum, Der Nationalsozialismus im öffentlichen Bewusstsein der Bundesrepublik Deutschland. Kulturen der Vergangenheitsaufarbeitung 19491999, in: M.-L. Recker/B. Jellonek/B. Rauls (Hgg.), Bilanz: 50 Jahre Bundesrepublik Deutschland (= Schriftenreihe Geschichte, Politik \& Gesellschaft der Stiftung Demokratie Saarland 5), St. Ingbert 2001, 221-235.

WolfRUm 2006: E. Wolfrum, Die geglückte Demokratie. Geschichte der Bundesrepublik Deutschland von ihren Anfängen bis zur Gegenwart, Stuttgart 2006.

WOLFRUM 2020: E. Wolfrum, Der Aufsteiger. Eine Geschichte Deutschlands von 1990 bis heute, Stuttgart 2020.

Yoshitake 2010: S. Yoshitake, Aretē and the Achievements of the War Dead. The Logic of Praise in the Athenian Funeral Oration, in: Pritchard 2010a, 359-377.

ZAHAVI 2020: Viel mehr als ein schillernder Opportunist. Regisseur D. Zahavi über Krupp-Chef Berthold Beitz, URL: https://www.deutschlandfunkkultur.de/regisseurdror-zahavi-ueber-krupp-chef-berthold-beitz-viel.1008.de.html?dram:article id=467903 (zuletzt aufgerufen am 02.02.2020).

ZiOLKOwsKi 1981: J. E. Ziolkowski, Thucydides and the Tradition of Funeral Speeches at Athens, Salem 1981.

ZÜLSDORF-KERSTING 2007: M. Zülsdorf-Kersting, Sechzig Jahre danach. Jugendliche und der Holocaust. Eine Studie zur geschichtskulturellen Sozialisation, Berlin 2007.

\section{Kontakt zum Autor:}

Seminar für Geschichte und Geschichtsdidaktik

Europa-Universität Flensburg

Auf dem Campus 1

D - 24943 Flensburg

E-Mail: Nils.Steffensen@uni-flensburg.de

\section{(cc) EY}

Dieser Beitrag ist lizenziert unter einer Creative Commons Namensnennung - 4.0 International Lizenz. 